\title{
FUNCTIONAL COOPERATION BETWEEN THE \\ CAUDATE NUCLEUS AND THE POSTERIOR THALAMUS IN VISUAL INFORMATION PROCESSING
}

Doctoral Thesis

\author{
Alice Rokszin, MD \\ Supervisors: \\ György Benedek, MD, PhD, DSc \\ Attila Nagy, MS, PhD \\ Department of Physiology
}

Faculty of Medicine, University of Szeged

Szeged, 2011 


\section{TABLE OF CONTENTS}

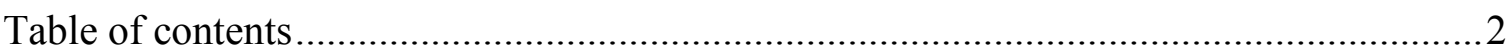

List of publications providing the basis and related to the topic of the thesis .................... 4

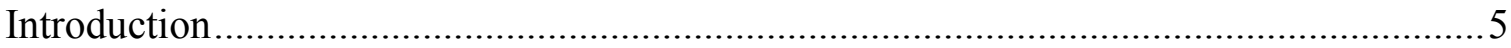

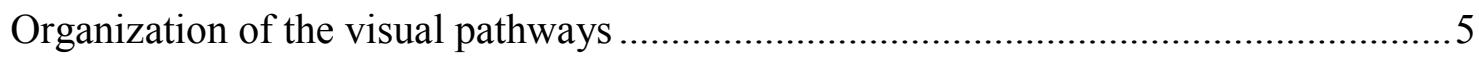

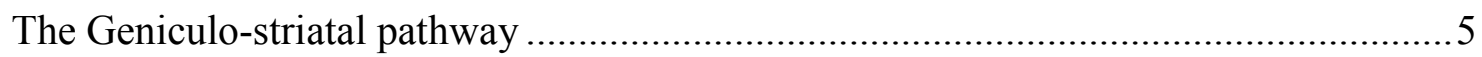

Extrageniculo-extrastriatal pathways and the ascending tectofugal system ..................6 6

Visual properties of the neurons within the ascending tectofugal system ..................... 8

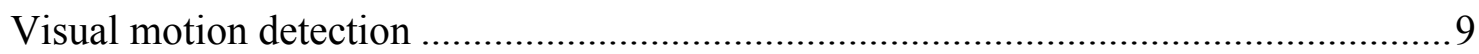

Role of the ascending tectofugal system in visual motion detection ............................ 9

Missing information about the ascending tectofugal system ................................... 10

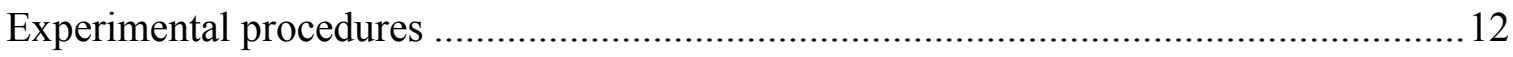

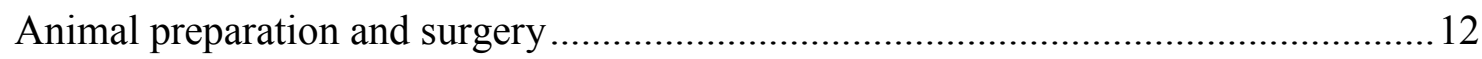

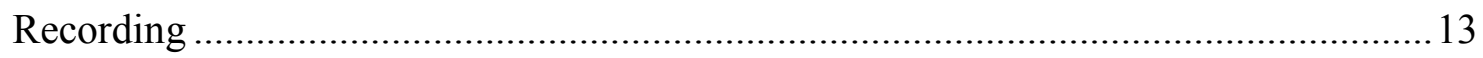

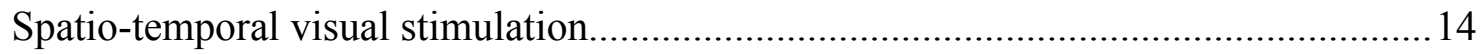

Visual stimulation during the investigation of cooperation ..................................... 14

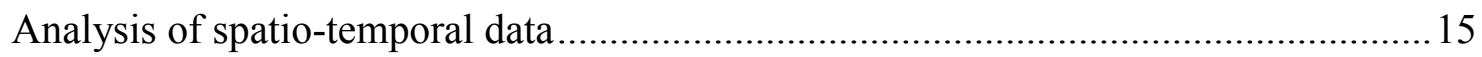

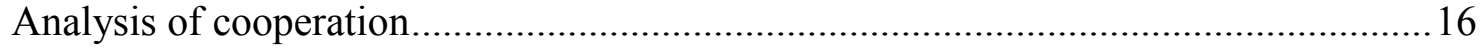

Measurment of visual response onset latencies...................................................20

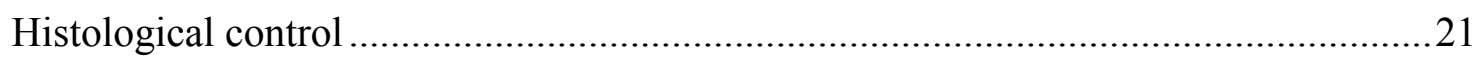

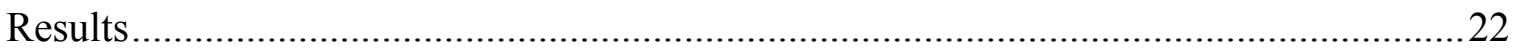

Comparative analysis of spatio-temporal visual properties in the ascending tectofugal

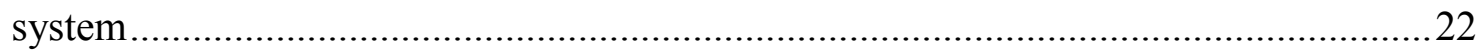

Spatio-temporal response characteristics of neurons in the ascending tectofugal

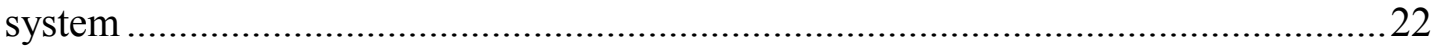

Comparision of the spatio-temporal spectral response profiles in the ascending

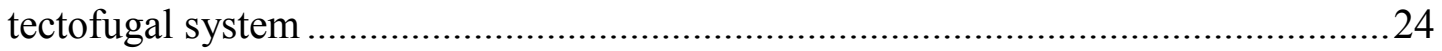

Cross-correlation analysis between the caudate and the suprageniculate nucleus.........26

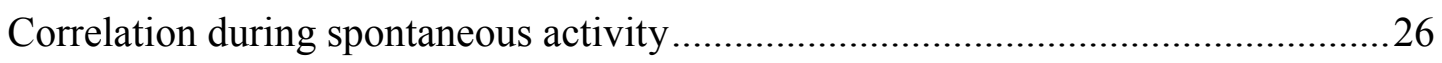




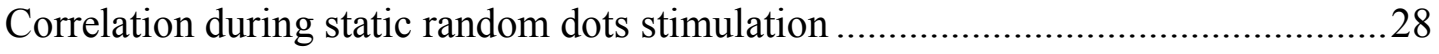

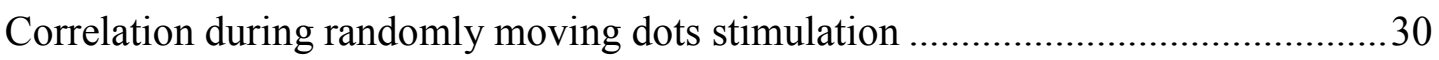

Analysis of the visual onset response latencies in the $\mathrm{Sg}$ and the $\mathrm{CN}$.......................32

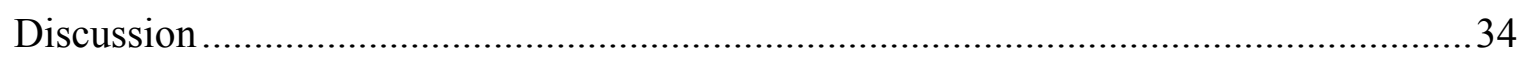

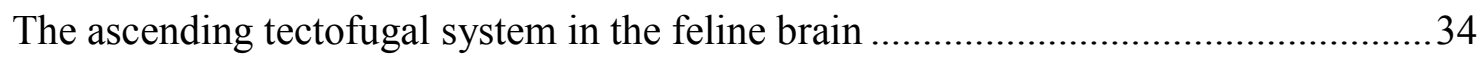

Spatio-temporal visual response properties in the ascending tectofugal system ...........36

Assumed role of the ascending tectofugal system in visual motion detection................37

Homology between the primate and feline brain regarding structures take part in visual

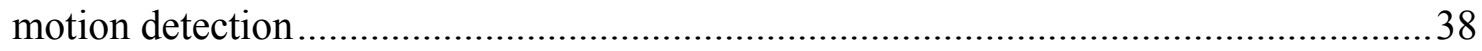

Neuronal networks and functional coopertion within the ascending tectofugal system 39

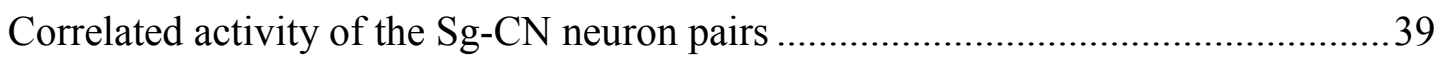

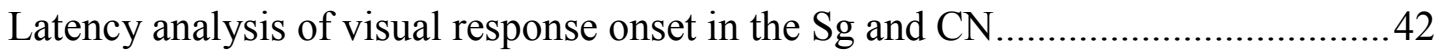

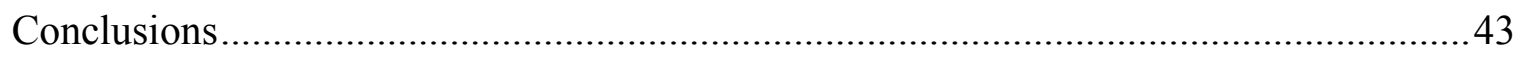

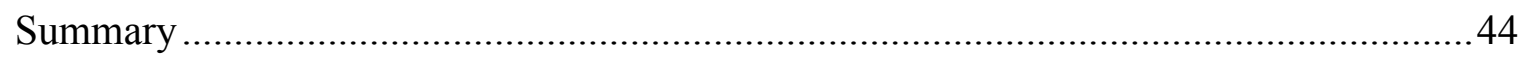

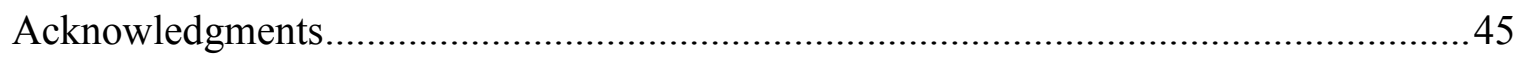

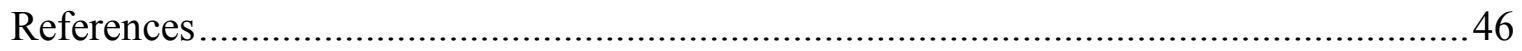



TO THE TOPIC OF THE THESIS

I. Spatio-temporal visual properties in the ascending tectofugal system.

Rokszin A, Márkus Z, Braunitzer G, Berényi A, Wypych M, Waleszczyk WJ, Benedek G, Nagy A

Central European Journal of Biology, 5: 21-30. (2010)

IF: 0.685

II. Visual pathways serving motion detection in the mammalian brain.

Rokszin A, Márkus Z, Braunitzer G, Berényi A, Benedek G, Nagy A.

Sensors 10: 3218-3242. (2010)

IF: 1.771

III. Visual stimulation synchronizes or desynchronizes the activity of neuron pairs between the caudate nucleus and the posterior thalamus

Rokszin A, Gombkötő P, Berényi A, Márkus Z, Braunitzer G,

Benedek G, Nagy A

Brain Research, DOI:

IF: 2.632 
Since the beginnings of the history of neuroscience, the visual system has been in the focus of scientific research. Related structures of the mammalian brain are probably among the best characterized, although there are still a lot of questionable aspects. The central nervous system is composed of a cooperating network of cortical areas and subcortical structures. The linear transmission of information is a widely accepted theory in neurophysiology (Hubel \& Wiesel, 1962, 1965; Stone et al., 1979; Lennie, 1980; Nowak \& Bullier, 1997). However, in the recent years more and more evidence emerged to support the hypothesis that the central nervous system is a web of finely tuned loops. Until now the visual system has been thought to consist of parallel pathways. Thus, although we call these information transmission routes 'pathways' in the visual system, there are more and more facts to suggest that these are rather loops, or information processing circuits. Moreover, it is highly probable that the information flow is not unidirectional, rather bidirectional, characterized by continuous feed-backs.

The existence of parallel loops in the mammalian brain now is no more an assumption, but an established fact, primarily in the motor system, where the circuits in the basal ganglia form the basic elements of the finely tuned coordination of motor actions (McHaffie et al., 2005). We assume that the visual system is also built up of such circuits, and the complex visual information is processed in a complex network of parallel loops.

\section{THE GENICULO-STRIATAL PATHWAY}

According to the classical approach, the visual system starts from the retina and ends in the visual cortices, which are hierarchically organized areas in the central nervous system. Different aspects of the visual information are processed and transmitted by parallel, segregated pathways. The separation of different information processing pathways originates in the retina, where the various types of ganglion cells serve the purposes of basic visual information processing. The different features, such as motion, 
colour, texture, and 3-dimensional extent are transmitted through parallel routes. The next stage of information transmission is one of the thalamic nuclei, the lateral geniculate nucleus (LGN), from where information is further transmitted to the primary visual cortex (V1; A17 in the feline brain, Brodmann 17 in the human brain), which is also called striate cortex. This pathway is known as the geniculo-striatal pathway, and is mainly responsible for the processing of elementary visual information, like luminance, orientation, and colour.

\section{EXTRAGENICULO-EXTRASTRIATAL PATHWAYS AND THE ASCENDING TECTOFUGAL SYSTEM}

Beside the geniculo-striatal pathway, there exists another similarly important pathway, called extrageniculo-extrastriatal pathway. The existence of separate geniculate and extrageniculate visual systems in the feline brain has been proven in both morphological and physiological studies. Beside the LGN, a total of nine subcortical structures have been found to receive afferents directly from the retina (Rosenquist, 1985). Of these structures, the superior colliculus (SC), in whose neurons the tectal extrastriatal pathway originates, has attracted the most research interest during the past twenty years. In this period, the morphological and physiological properties of the extrageniculate pathway in the cat brain have been described in detail.

Different association cortices, like areas surrounding the suprasylvian sulcus in the feline brain, the middle temporal area (MT, also known as V5) (Zeki et al., 1991), the medial superior temporal area (MST), the superior temporal polysensory area (STP) in the primate brain, have fundamental role in the extrageniculate system. Palmer et al. (1978) gave the first description of the cortical regions surrounding the suprasylvian sulcus and it is widely accepted that the lateral suprasylvian (LS) cortex consists of six visuotopically organized areas: the anteromedial and anterolateral lateral suprasylvian areas (AMLS and ALLS), the posterior medial lateral suprasylvian area (PMLS), the posterior lateral lateral suprasylvian area (PLLS), and the dorsal and ventral lateral suprasylvian areas (DLS and VLS). PMLS and AMLS have extensive connectivity with the anterior ectosylvian visual area (AEV) (Olson \& Graybiel, 1987; Ouellette et al., 2004; Symonds \& Rosenquist, 1984 a,b; Miceli et al., 1985). During decades of research, confirmation of the homology between the feline and the primate brain was one of the 
major challenges. The PMLS area of the feline brain is generally considered to be a homologue of the primate MT, known to be an essential element of the visual motion pathway of the primate brain at a lower level than the MST (Zeki, 1974; Felleman \& Van Essen, 1991; Payne, 1993). Previously, the PLLS was regarded as a possible analogue of the MST (Payne, 1993), but finally Li et al. (2000) described the significantly different visual properties of the PLLS neurons (e.g., sensitive to fewer types of stimuli, the optic flow selectivity is not as good as in MST, while it responds better and more selectively to radial motion), so this area cannot be considered as an equivalent of the MST. Beyond these cortices subcortical structures, the posterior part of the thalamus, such as the pulvinar and suprageniculate nucleus $(\mathrm{Sg})$, portion of the midbrain, as the $\mathrm{SC}$, and the basal ganglia (especially the caudate nucleus $(\mathrm{CN})$ ) are also essential elements of the extrageniculate system.

Beyond the fact that $\mathrm{CN}$ is an important element in the ascending tectofugal system, it is also the main input structure of the basal ganglia loop. Within this loop CN plays an important role in the motor control. It is involved not only the guidance of fine movements, but in the adjustment of visuomotor behaviour as well, and it contributes to the control of visually guided oculomotor and skeletomotor functions (Schwarz et al., 1984; Lynd-Balta \& Haber, 1994; Barneoud et al., 2000; Hikosaka et al., 2000). Accordingly, a number of studies have been carried out to clarify the role of $\mathrm{CN}$ in visual information processing (Pouderoux \& Freton, 1979; Rolls et al., 1983; Strecker et al., 1985; Hikosaka et al., 1989; Kolomiets, 1993; Brown et al., 1995; Nagy et al., 2003c). However, there is still some degree of uncertainty concerning the pathways conveying sensory information to the basal ganglia. Earlier morphological findings in cats and rabbits stressed the predominant role of the geniculostriate pathway that conveys visual information toward CN (Webster, 1965; Hollander et al., 1979). However, recent morphological and physiological studies have seemed to support the suggestion that the extrageniculate ascending tectofugal pathways project to the $\mathrm{CN}$ in amniotes, while in reptiles the $\mathrm{Sg}$ and in birds the Rotund Nucleus seem to be the thalamic input structures of CN (Guirado et al., 2005; Harting et al., 2001). 


\section{VISUAL PROPERTIES OF THE NEURONS WITHIN THE ASCENDING TECTOFUGAL SYSTEM}

Experiments for the characterization of the physiological visual properties within the ascending tectofugal system started immediately after the detection of visually active neurons in the AEV. All the experiments were performed on anesthetized, immobilized, artificially ventilated cats with extracellular single unit recordings. Early observations demonstrated that AEV neurons possess unique receptive field properties (Mucke et al., 1982; Benedek et al., 1988). Very similar receptive field properties have been found in neurons in the Insular Visual Area (IVA) (Benedek et al., 1986; Hicks et al., 1988b), in the retino-recipient intermediate and deep layers of the SC (Stein \& Meredith, 1993) and in the Sg (Benedek et al., 1997). Hence, we can summarize the visual receptive field properties, irrespectively of the region in question. A striking physiological characteristic of these neurons (i.e. in the AEV, IVA, Sg and SC) is the extreme sensitivity of the neurons to movement in their receptive field. The neurons are primarily sensitive to very small stimuli moving very rapidly in a specific direction in their huge receptive field (Benedek et al., 1988; 1997; Hicks et al., 1988b). A substantial proportion (approximately 20 percent) of the AEV neurons responds optimally to stimuli moving at a speed of higher than 1000 degree/second (deg/s). No other area of the cat cortex contains such a high proportion of neurons that respond optimally to very fast stimuli. Most of the neurons are highly direction-selective. Although the visual receptive field properties have been extensively investigated, the visual receptive field size and retinotopical organization within the AEV remained a matter of controversy. Some studies have indicated the complete absence of retinotopic organization (Mucke et al., 1982; Benedek et al., 1988; Hicks et al., 1988b) in contrast with the impressive retinotopy in the geniculostriatal pathway (Tusa et al., 1978). Our previous results demonstrated that the visual neurons in the $\mathrm{AEV}, \mathrm{Sg}$ and the $\mathrm{CN}$ have extremely large receptive fields, which consistently include the area centralis and cover almost the whole visual field of the examined eye (Benedek et al., 1988; Nagy et al., 2003a,b; Eördegh et al., 2005). Furthermore, the spatio-temporal response properties are also similar in the structures of this system (Nagy et al., 2003c; Paróczy et al., 2006; Nagy et al., 2008). Yet, a detailed, comprehensive analysis of these visual properties has been missing until now. 
One of the most important features to be detected and analysed by the visual system is rapid change in the visual field. This is the process through which humans and animals orient themselves to their own movements and those of the objects comprising their environment, via light-transmitted signals processed by their visual system. Changes in the visual environment can provide the animal information crucial for its survival, e.g. that a predator or prey is around, just to mention the most trivial of possibilities. Beside the detection of light and dark, this ability seems to be the oldest and most important feature of the visual system. Despite the fact that a wide range of visual animals lack binocular or colour vision, the visual perception of motion seems to be a general property that can be difficult to substitute (Nakayama, 1985). Since the beginnings of the research into vision, where and how related procedures take place in the brain has been a key question (Goodale \& Milner, 1992; Ungerleider \& Mishkin, 1982).

\section{ROLE OF THE ASCENDING TECTOFUGAL SYSTEM IN VISUAL MOTION DETECTION}

According to the classical theory, the above mentioned extrastriate structures play subservient and complementary roles in motion sensation. The two-stage motion processing theory is a generally accepted hypothesis (Adelson \& Movshon, 1982; Welch, 1989; Derrington \& Suero, 1991; Albright \& Stoner, 1995). It assumes that at the first stage, analysis of the object's features occurs as broken down to one-dimensional components in the early visual areas, depending on orientation-selective mechanisms sensitive to the motion of individual component contours. The second stage is regarded as that of pattern motion detection, possibly carried our by higher extrastriate cortical areas integrating the output of the first stage analyzers to construct the actual movement direction of the coherent pattern. Nevertheless, more and more evidence is found to raise the suspicion that the two-stage theory might be incomplete for modelling the visual motion analysis (Clifford \& Ibbotson, 2002; Andersen, 1997; Li et al. 2001). Rather, the extrastriate structures may have equal and coordinate functions as they receive direct input from the lower, primary stages of the visual stream, not only through indirect connections from the primary visual cortical areas. Therefore, it has to be stressed that the two systems exist and work simultaneously together and not separately, without any 
connection. Consequently, for proper visual sensation, the harmonized, mutual interaction between the two systems is essential.

\section{MISSING INFORMATION ABOUT THE ASCENDING TECTOFUGAL SYSTEM}

As mentioned above, in previous studies, the physiological features of the elements within the ascending tectofugal system were characterized one by one. These analyses suggested that similar spatio-temporal visual properties might exist within this system. Accordingly, we decided to perform a comprehensive analysis of these visual features within the structures along this pathway to confirm our assumption. After having successfully replicated the previously described results, we aimed at getting a more detailed analysis of the nature of actual information transmission between two important structures within this system; that is, we intended to analyse the physiological connection and the functional cooperation between the $\mathrm{Sg}$ and the $\mathrm{CN}$.

There are several approaches in neurophysiology to investigate such connections. We could directly stimulate one area and observe the changes in the other, which might yield direct evidence. This kind of analysis is a quite sophisticated and state-of-the-art method, however, it is really challenging to implement. With the apparatus at our disposal, indirect methods seemed to be more appropriate. Accordingly, we evaluated the temporal interaction between the two structures with cross-correlation analysis, from which we got information regarding the cell-cell interaction. In the next step, we analysed the visual response onset latencies, to provide further support for our hypothesis, namely, that beyond the same physiological properties, a real, scientifically justifiable functional connection exists between the $\mathrm{Sg}$ and the $\mathrm{CN}$. 
- to provide a detailed and comprehensive physiological characterization of the spatio-temporal visual response properties in the ascending tectofugal system

- to investigate the cooperation between the suprageniculate nucleus of the posterior thalamus $(\mathrm{Sg})$ and the caudate nucleus $(\mathrm{CN})$

○ using cross-correlation analysis

○ using latency analysis

- to describe the type of connectivity between the above mentioned structures, as in:

- synchronization and/or temporal coupling between the structures

- effect of visual stimulation on either of these hypothesised relations 


\section{EXPERIMENTAL PROCEDURES}

\section{ANIMAL PREPARATION AND SURGERY}

The experiments were performed on eighteen adult cats of either sex, weighing between $2.5-4 \mathrm{~kg}$. All experimental procedures were carried out to minimize the number of the animals involved and followed the European Communities Council Directive of 24 November 1986 (86 609 EEC) and the National Institute of Health guidelines for the care and use of animals for experimental procedures. The experimental protocol had been accepted and approved by the Ethics Committee for Animal Research of Albert SzentGyörgyi Medical and Pharmaceutical Center of the University of Szeged.

The animals were initially anaesthetized with ketamine hydrochloride (Calypsol, $30 \mathrm{mg} / \mathrm{kg}$ i.m.). To reduced salivation and bronchial secretion a subcutaneous injection of $0.2 \mathrm{ml} 0.1 \%$ atropine sulphate was administered preoperatively. After the cannulation of the femoral vein and the trachea, the animals were placed in a stereotaxic headholder. All wounds and pressure points were treated generously with local anesthetic (1\%, procaine hydrochloride). Throughout the surgery the anaesthesia was continued with halothane (Fluothane, 1.6\%) in air. The animals were immobilized with an initial $2 \mathrm{ml}$ intravenous bolus of gallamine triethiodide (Flaxedil, $20 \mathrm{mg} / \mathrm{kg}$ ), and artificial ventilation was introduced. During recording sessions, a liquid containing gallamine triethiodide (8 $\mathrm{mg} / \mathrm{kg} / \mathrm{h})$, glucose $(10 \mathrm{mg} / \mathrm{kg} / \mathrm{h})$ and dextran $(50 \mathrm{mg} / \mathrm{kg} / \mathrm{h})$ in Ringer lactate solution was infused continuously at a rate of $4 \mathrm{ml} / \mathrm{h}$. The eye contralateral to the cortical recording site was treated locally with atropine sulfate (1-2 drops, $0.1 \%)$ and phenylephrine hydrochloride (1-2 drops, 10\%) to dilate the pupils and block accommodation and to retract the nictitating membranes, respectively, and was equipped with a +2 dioptre contact lens. The ipsilateral eye was covered during stimulation and recordings. During the recording session, anaesthesia was maintained with a gaseous mixture of air and halothane $(0.8-1.0 \%)$. The depth of anaesthesia was monitored by continuously checking the end-tidal halothane values and by monitoring heart rate (electrocardiogram) and brain activity (electroencephalogram, EEG). By adjustment of the concentration of halothane, high-amplitude, slow-frequency EEG activity with sleep spindles could be kept up. We also checked repeatedly whether any of the experimental procedures or a forceful 
pressing of the forepaws could induce desynchronization. The minimum alveolar anaesthetic concentration (MAC) values calculated from the end-tidal halothane readings were kept in the range given by Villeneuve and Casanova (2003). The end-tidal halothane concentration, $\mathrm{MAC}$ values and the peak expired $\mathrm{CO}_{2}$ concentrations were monitored with a capnometer (Capnomac Ultima, Datex-Ohmeda, Inc.). The $\mathrm{O}_{2}$ saturation of the capillary blood was monitored by pulse oxymetry. The peak expired $\mathrm{CO}_{2}$ concentration was kept within the range $3.8-4.2 \%$ by adjustment of the respiratory rate or volume. The body temperature of the animal was maintained at $37^{\circ} \mathrm{C}$ by a warm-water heating blanket with an automatic control. The craniotomy was made with a dental drill to allow a vertical approach to the appropriate brain structures. The dura mater was covered with a $4 \%$ solution of $38^{\circ} \mathrm{C}$ agar dissolved in Ringer's solution.

\section{RECORDING}

Extracellular single-cell recordings were performed in the SC, the Sg and the $\mathrm{CN}$ with tungsten microelectrodes (A-M Systems, Inc., USA) with an impedance of 2-4 M $\Omega$. During the investigation of cooperation response of single neurons were simultaneously recorded with the same type of electrodes. Vertical penetrations were made within Horsley-Clarke coordinates anterior 1-4, lateral 2-6 in the stereotaxic depths from 11-15 in case of the $\mathrm{SC}$, while, $\mathrm{Sg}$ single unit recording sites were between the coordinates anterior 4.5-6.5 and lateral 4-6.5 at the stereotaxic depth between 16-18. CN neurons were reached between the coordinates anterior $12-16$ and lateral 4-6.5 at the stereotaxic depths between 12 and $19 \mathrm{~mm}$. Microelectrodes were advanced with a microstepper. Action potentials were amplified, displayed on an oscilloscope and transformed through a loudspeaker. The visual responsiveness of the neurons was tested and the extents of the visual receptive fields were estimated subjectively by listening to the responses of the single units to moving visual stimuli generated by a hand-held lamp. The receptive fields were huge; they consistently included the area centralis and covered almost the whole visual field of the investigated eye. Furthermore, no signs of retinotopic organization was found. 
For the spatio-temporal visual stimulation of the neurons (within the $\mathrm{Sc}, \mathrm{Sg}$ and $\mathrm{CN}$ ), an 18-inch computer monitor (refresh rate: $85 \mathrm{~Hz}$ ) was placed $42.9 \mathrm{~cm}$ in front of the animal. The diameter of the stimulation screen was $22.5 \mathrm{~cm}$. The stimulation area subtended $30 \mathrm{deg}$. The mean luminance of the screen was $23 \mathrm{~cd} / \mathrm{m}^{2}$. For the study of the spatio-temporal characteristics of the cells, high-contrast (96\%), drifting sinewave gratings were used. Different parts of the grating had different luminance, but the screen as a whole was isoluminant during different spatio-temporal combinations. Each grating (the gratings were moved) had a particular spatial and temporal frequency. These parameters are not independent of each other. The spatial frequency and the speed of the movement determine the temporal frequency or the spatial and temporal frequencies that were used to calculate the real velocity of movement. The sinusoidal gratings were moved along four different axes in eight different directions (0-315 deg at $45 \mathrm{deg}$ increments) to find the optimal direction for each unit. The optimal direction of each unit was further used to describe its spatial and temporal characteristics. The spatial frequencies ranged between 0.025 and $0.95 \mathrm{c} / \mathrm{deg}$. The temporal frequencies were investigated between 0.07 and $41.08 \mathrm{~Hz}$. Altogether 110 spatio-temporal frequency combinations were presented to each investigated neuron in a random order. Each spatio-temporal frequency combination was presented at least 12 times. The interstimulus interval was $1000 \mathrm{~ms}$.

\section{VISUAL STIMULATION DURING THE INVESTIGATION OF COOPERATION}

The stimulus we used to investigate the cooperation between the $\mathrm{Sg}$ and $\mathrm{CN}$ during visual information process, was a random dot kinetogram generated in Matlab (MathWorks Inc., Natick, MA), using the Psychophysics Toolbox extension (Brainard, 1997; Pelli, 1997), and presented on an 18-inch computer monitor (refresh rate: $85 \mathrm{~Hz}$ ) placed $42.9 \mathrm{~cm}$ in front of the animal. The steady-state luminance of a stationary dot was $10 \mathrm{~cd} / \mathrm{m}^{2}$, while the background luminance was $2 \mathrm{~cd} / \mathrm{m}^{2}$. The stimulus consisted of 3 parts: first a blank, black screen was presented for $1500 \mathrm{~ms}$ to obtain spontaneous activity without visual stimulation; then, for another $1500 \mathrm{~ms}$, random stationary dots were presented; finally, the same dots were moved for $1500 \mathrm{~ms}$, each in a random direction. The stimuli contained 200 white square dots, moved at the speed of $5 \mathrm{deg} / \mathrm{s}$. The diameter 
of the stimulation screen was $22.5 \mathrm{~cm}$, therefore it subtended $30 \mathrm{deg}$ and covered practically the whole receptive field. The diameter of each dot was 3 pixels $(8.6$ mins of arc). The stimulus sequence was repeated 500 times, thus the average duration of one spike-pair registration was about $35-40 \mathrm{~min}$. It has to be stressed that this type of stimulus is different from the sinusoidally modulated drifting gratings that we used to determine the spatio-temporal visual properties of these structures during our previous studies. However, it is likely that these neurons could generate bigger response to grating stimuli, but if we want to stimulate two neurons with different spatio-temporal properties, the random dot kinematogram seems to be the most appropriate tool, and not a grating with special spatial and temporal features. Moreover, in random moving dot stimulation there is no preferred direction of motion, and in our case it is a big advantage, since a remarkable portion of the $\mathrm{CN}$ and $\mathrm{Sg}$ neurons yield direction preference, and it is possible that the two neurons within a simultaneously recorded pair prefer different directions. In this case a moving visual stimulus without direction preference may be the best possible choice. That is, a random dot kinematogram seems to be an optimal input to stimulate two simultaneously recorded neurons at the same time with the biggest possibility.

\section{ANALYSIS OF SPATIO-TEMPORAL DATA}

The prestimulus (stationary sinusoidal grating) time and the peristimulus (drifting sinusoidal grating) time was $1000 \mathrm{~ms}$. Single-cell discrimination was preformed with the help of a spike-separator system (SPS-8701, Australia). Neuronal activity, the number and temporal distribution of the action potentials were recorded during stimulation, and stored as peristimulus time histograms (PSTHs) for further off-line analysis. The net discharge rate, calculated as the difference between the mean firing rate of the cell obtained during stimulus movement (peristimulus period) and the background activity corresponding to the mean activity during the $200 \mathrm{~ms}$ preceding movement in the prestimulus period, was used to characterize the response amplitude of the neurons. We defined the net firing rate as response when a t-test indicated a significant $(p<0.05)$ difference between the two values. The spatial and temporal high-frequency cut-off was defined as the frequency at which the net response (after the subtraction of the spontaneous activity) of the cell fell to one-tenth of the maximum (Saul \& Humphrey, 1990). This was regarded as a measure of the spatial and temporal resolution. The spatial 
and temporal frequency tuning bandwidths measured at half-height of the spatial and temporal frequency-tuning curve of the band-pass units were also analysed.

The large sample size limited the analysis to include only the neuronal responses where the cells showed stable basal activity during the whole recording. Statistical analyses of the data were performed with the Statistica for Windows (StatSoft Inc., USA) and Matlab (MathWorks Inc., USA) software packages.

\section{ANALYSIS OF COOPERATION}

The signal containing multiunit activity was sampled at $20 \mathrm{kHz}$, and stored for off-line analysis (Datawave SciWorks, Version 5.0, DataWave Technologies Corporation, USA). Amplified neuronal activity was band-pass filtered between 300 and $3000 \mathrm{~Hz}$. Spikes were extracted after manually adjusted amplitude threshold detection, and clustered based on the automatically calculated characteristic parameters of the extracted spike waveforms (peak and through amplitude and timing, $1^{\text {st }}$ and $2^{\text {nd }}$ principal components). Proper discrimination of simultaneously recorded neurons' spikes' waveforms was confirmed by the spike-trains autocorrelogram. On the autocorrelogram dip at 0 timelag indicates that the spike separation was correct (Figure 1). 

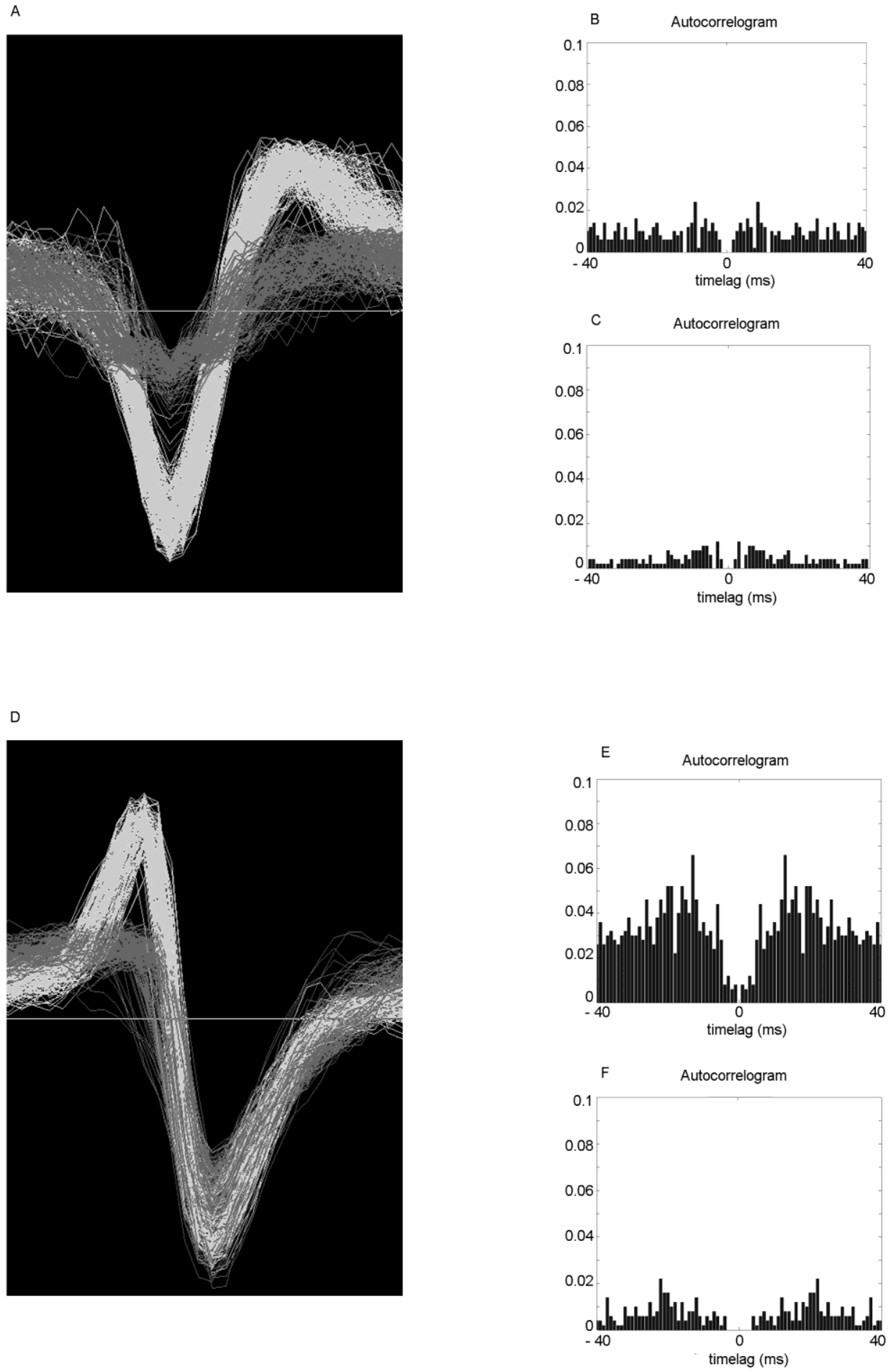

Figure 1. Spike sorting. A and D show the results of spike sorting in one $\mathrm{Sg}$ and one $\mathrm{CN}$ recording, respectively. B, C, E and F show the autocorrelograms of the sorted neurons. 
The neuronal activity, that is, the number and temporal distribution of the action potentials, was recorded during stimulation, and stored as peristimulus time histogram (PSTH) for further off-line analysis. The net discharge rate, calculated as the difference between the mean firing rate of the cell obtained during visual stimulation (peristimulus period; stationary or moving) and the background activity corresponding to the mean activity during the $200 \mathrm{~ms}$ time preceding visual stimulation in the prestimulus (blank screen) period, was used to characterize the response amplitude of the neurons. We defined the net firing rate as response when a t-test indicated a significant $(\mathrm{p}<0.05)$ difference between the two values. All analysed and presented neurons both in the Sg and $\mathrm{CN}$ showed significant response to visual stimulation.

Monosynaptic interactions can only be inferred indirectly from an extracellular signal. This is typically done by examining counts of co-occurrences of spiking in the putative pre- and postsynaptic neurons at various differential time lags, as shown by cross-correlogram. Cross-correlations were computed off-line, using the Matlab software package (MathWorks Inc., Natick, MA). The whole time-course of a trial and then each of the different stimulus conditions was analysed separately. The algorithm for crosscorrelation analysis was the following: out of a given pair, one neuron was designated as reference. For each of the spikes fired by this neuron (within the particular time window), the time delays relative to each of the spikes of the other (target) neuron were calculated and plotted in a histogram of typically $40 \mathrm{msec}$ delay and a bin width of 1 msec. This procedure was repeated for all spikes and all trials, summing up all entries and yielding the raw cross-coincidence histogram, or, with other words the raw crosscorrelogram.

Informally, monosynaptic interactions are inferred from sharp peaks or troughs in the cross-correlogram at short latencies. An alternative explanation is that the temporal relationship in spiking is due to temporal relationships between the two neurons' inputs, in the absence of a monosynaptic interaction.

Repetitive presentation of the visual stimulus may cause a coinciding change in the activity pattern of both recorded neurons, however, this simultaneously appearing costimulation is a result of the visual responsiveness per se. This simultaneous, but independent change in the firing rates introduces an event-locked pseudo-relationship 
between the investigated neurons. Therefore, the covariation in the firing rates of the two stimulated cells must be removed before considering the peaks of the cross-correlograms to be relevant.

The easiest way to correct this stimulus-induced relationship is to construct a shifted or shuffled cross-correlogram (Perkel et al., 1967; Hirabayashi \& Miyashita, 2005), which is one of the most frequently used resampling methods for disambiguating dependencies. We created shuffled cross-correlograms by mismatching the trials of the two spike trains and correlating them. For the mismatching we used random permutation for trials' order; trials of the target neuron were randomly permuted 1000 times, generating 1000 'surrogate' data sets. The average and stimulus modulated firing rates of the cells were not altered by the shuffling process, but the physiological relationship between individual spikes of the neurons was eliminated; it is highly unlikely that spikes from one stimulus trial are affected by the previous or following trial's spike trains. The shuffled cross-correlogram is therefore a measure of coincidences caused by covariation of the firing rates induced by the stimulation. The shuffle corrected cross-correlogram is generally computed by averaging all the thousand individually generated shuffled crosscorrelograms then by subtracting this cross-correlogram (also known as shuffle predictor) from our raw cross-correlogram the event-locked coincidences could be removed.

In the present study we also applied another resampling method, the jitter resampling method, designed especially for the analysis of such fine-temporal structures in neuronal spike trains that cannot be explained by slowly varying firing rates (Abeles \& Gat, 2001, Hatsopoulos et al. 2003). In this case, each spike in the target neuron is randomly and independently perturbed on a symmetrically centred uniform interval of [-5 $\mathrm{ms},+5 \mathrm{~ms}]$ to create a surrogate data set. The process was repeated 1000 times. Afterwards, we calculated the cross-correlation function between the reference neuron and the jittered target neuron, we got 1000 jitter modified cross-correlograms, and by calculating the mean of the 1000 jitter modified cross-correlograms and having extracted this from the raw cross-correlogram, we got the jitter corrected cross-correlogram.

A correlation value at a certain time bin of the real non-corrected crosscorrelogram is considered as significant if it lies out of the $95 \%$ confidence interval values defined by the surrogate correlation values for that timelag (local acceptance 
band). To avoid the statistical error of multiple comparisons, instead of repetitively applying this rule to all timelags in a cross-correlogram, we calculated a global acceptance band according to Fujisawa et al. (2008). Briefly, the series of 5\% local confidence interval values determine a so-called local acceptance band, where the chance that one of the surrogate correlograms breaks this acceptance band at a certain bin is $5 \%$, which probability grows exponentially by comparing at multiple bins. We raised the acceptance level in $0.1 \%$ steps, until only $5 \%$ of the 1000 surrogate cross-correlograms broke the new, stricter confidence interval (global acceptance band), with respect to all of the bins.

We accepted a peak in a cross-correlogram as significant if we found it significant with both the shuffle and the jitter resampling methods. We calculated the crosscorrelation between the simultaneously recorded appropriate $\mathrm{Sg}-\mathrm{CN}$ cell pairs in three epochs of our recordings. The spontaneous activities $(300 \mathrm{~ms})$, the activities in response to random stationary dots $(1500 \mathrm{~ms})$ and the activities during random dot kinematogram stimulation (1500 ms) were analysed.

\section{MEASURMENT OF VISUAL RESPONSE ONSET LATENCIES}

The visual response onset latencies were calculated using the double sliding windows method developed in our laboratory. This technique combines the advantages of mathematical methods with the reliability of standard statistical processes. It is based on repetitive series of statistical probes between two virtual time windows. The first window (reference window) slides through the peristimulus period in 1 bin steps, and selects the portion that represents the maximum (or the minimum) frequency (depending on the excitatory or inhibitory quality of the neuronal response). A second window (sample window) then slides through, also in 1 bin steps. After each step, the program calculates the significance level between the spike frequencies of the two windows with the MannWhitney $U$ test. The latency of the responses is calculated from the time function of these $p$ values. A curve is fitted to the $p$ values, and the response onset latency is provided as the time interval between the start of the stimulation and the first point of the rising segment of the p curve, which is estimated by a second order difference (for a detailed description see: Berényi et al., 2007). 
At the end of the recording session, the animals were deeply anaesthetized with an intravenous injection of sodium pentobarbital (Euthanyl, $200 \mathrm{mg} / \mathrm{kg}$ ) and transcardially perfused with $500 \mathrm{ml}$ of warm saline $\left(37^{\circ} \mathrm{C}\right.$ ) followed by $1000 \mathrm{ml}$ of a $4 \%$ solution of paraformaldehyde in $0.1 \mathrm{M}$ phosphate buffer $(\mathrm{pH}$ 7.4). The brains were removed, and the location of the successful electrode penetrations was examined histologically. The brains were cut into coronal sections of $50 \mu \mathrm{m}$ and stained with Neutral Red. Recording sites were based on marks of electrode penetrations. 


\section{RESULTS}

COMPARATIVE ANALYSIS OF SPATIO-TEMPORAL VISUAL PROPERTIES IN THE ASCENDING TECTOFUGAL SYSTEM

We recorded altogether 73 visually active neurons from the superficial layers of the SC (SCs), 99 units from the intermediate layers of the SC (SCi), 101 from the $\mathrm{CN}$ and 105 from the Sg of the posterior thalamus. The subjective estimation of the extent of the visual receptive fields revealed contralateral and small receptive fields in the SCs. The mean size of the receptive fields in the superficial layers of the SC was 527.26 \pm 525.26 $\operatorname{deg}^{2}\left(n=73\right.$, range: 270 to $1960 \mathrm{deg}^{2}$ ). However, in the intermediate layers of the SC, we observed significantly larger receptive fields (Kolmogorov-Smirnov test, $p<0.001$ ), and the receptive field of some neurons covered parts of the ipsilateral visual field too. The mean size of the receptive fields in the SCi was $1890.69 \pm 1005.89 \operatorname{deg}^{2}(n=99$, range: 310.1 to 4643.9$)$. Concerning the $\mathrm{Sg}$ and the $\mathrm{CN}$, the receptive fields were significantly larger than those of both the SCs and SCi. The subjective estimation of the extent of the visual receptive fields revealed that they covered almost the whole visual field of the investigated eye and were consistently larger than $6000 \mathrm{deg}^{2}$. No signs of retinotopic organization were found within the Sg and the $\mathrm{CN}$.

\section{SPATIO-TEMPORAL RESPONSE CHARACTERISTICS OF NEURONS IN THE ASCENDING TECTOFUGAL SYSTEM}

The neurons in each structure (SCs, SCi, Sg, CN) responded optimally to very low spatial and very high temporal frequencies, exhibited low spatial and temporal resolution and narrow spatial and temporal frequency tuning (Figure 2). The majority of the neurons showed low pass spatial frequency tuning with no or only a slight attenuation of the response at low spatial frequencies. Spatial band-pass units were also recorded but we couldn't record spatial high-pass units in the ascending tectofugal system. Furthermore, the majority of the neurons showed band pass temporal frequency tuning with a clear optimal temporal frequency in the high temporal frequency domain. Temporal high-pass neurons were also found, but we recorded no temporal low-pass units in the SCs, SCi, Sg and the $\mathrm{CN}$ (for a more detailed description of the spatio-temporal properties of the SCs, 
$\mathrm{SCi}, \mathrm{Sg}$ and the CN see previous publications from our laboratory (Paróczy et al., 2006; Waleszczyk et al., 2007; Márkus et al., 2009; Nagy et al, 2008).
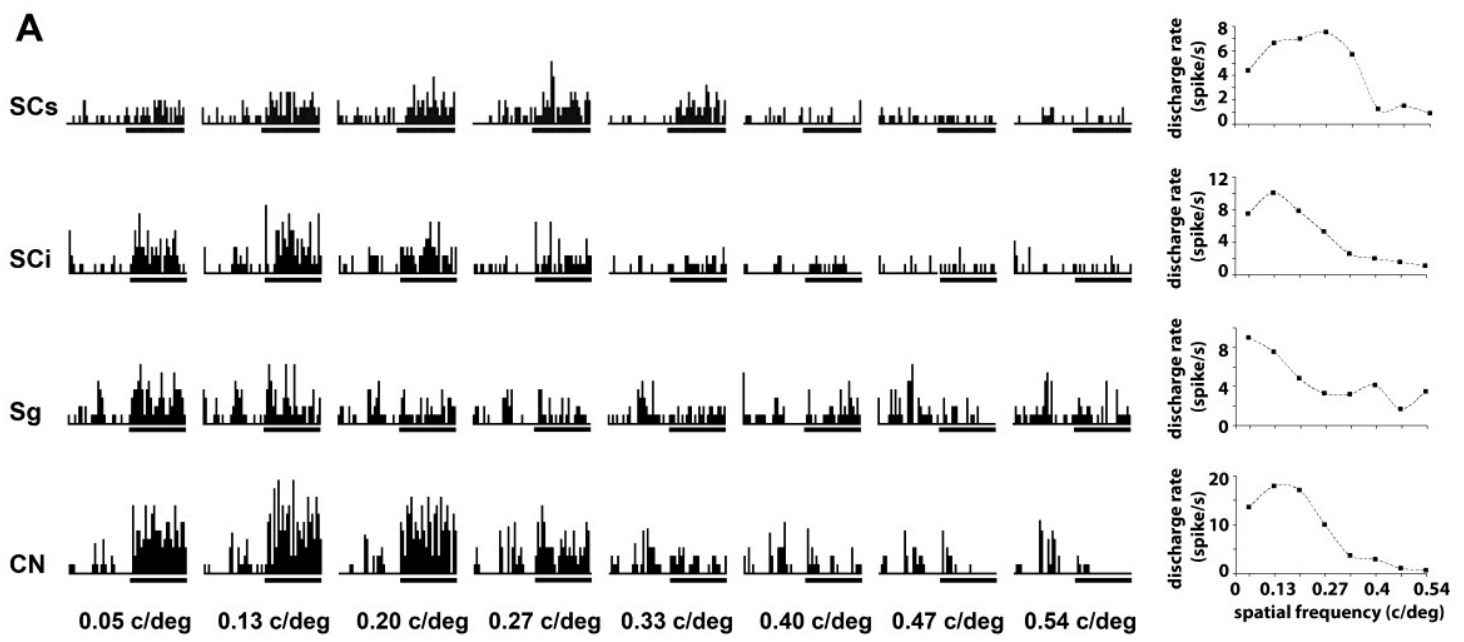

B
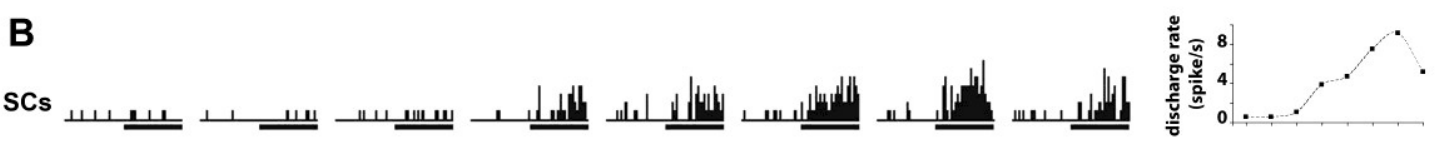

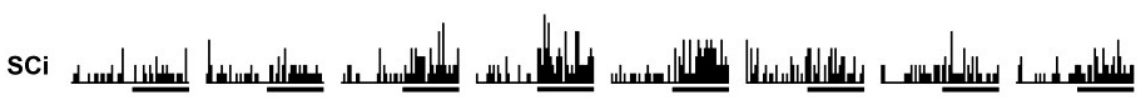

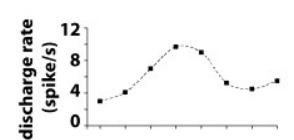

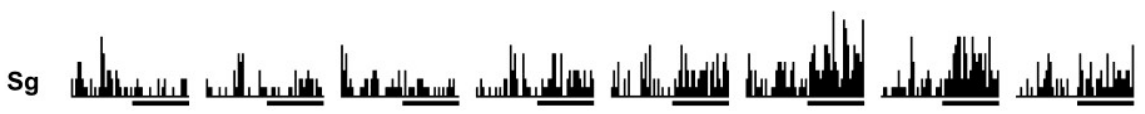

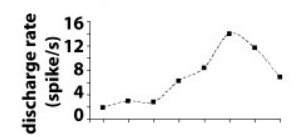

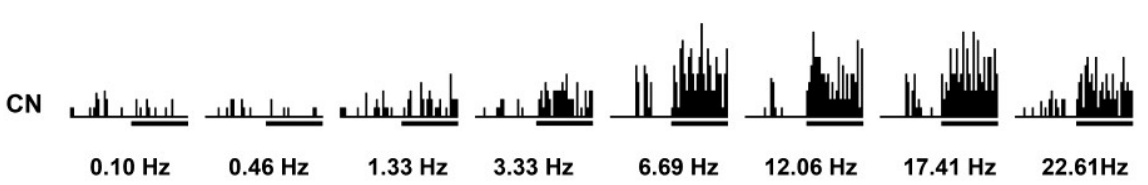

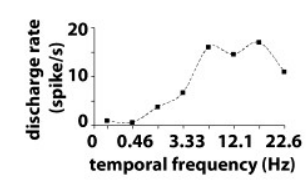

Figure 2. Neuronal responses to different spatial and temporal frequencies. Peristimulus time histograms (PSTH) of neurons from the superficial (SCs) and intermediate (SCi) layers of the superior colliculus (SC), suprageniculate nucleus $(\mathrm{Sg})$ and caudate nucleus $(\mathrm{CN})$ responding to drifting sinewave gratings with different spatial and temporal frequencies. Under the PSTHs the corresponding spatial and temporal frequencies of the sinewave gratings are given. The thick black lines under the PSTHs indicate the duration of the stimulus movement for $1000 \mathrm{~ms}$ (peristimulus time). At the end of each row of PSTHs the respective spatial or temporal frequency tuning curve is displayed. A: Responses of the SCs, SCi, Sg and $\mathrm{CN}$ neurons to eight different spatial frequencies. The neurons in each structure responded optimally to low spatial frequencies. B: Responses of the SCs, Sci, Sg and CN neurons to eight different temporal frequencies. The neurons responded optimally to high temporal frequencies. 
COMPARISION OF THE SPATIO-TEMPORAL SPECTRAL RESPONSE PROFILES IN THE ASCENDING TECTOFUGAL SYSTEM

The spatio-temporal spectral receptive field properties of the $\mathrm{SCs}$, the $\mathrm{SCi}$, the $\mathrm{Sg}$ and the $\mathrm{CN}$ were compared by one-way ANOVA (Figure $3 \mathrm{~A}$ ). Tukey post-hoc analysis was used for the pair-wise comparison of the individual structures.

The mean optimal spatial frequency was $0.10 \pm 0.01 \mathrm{c} / \mathrm{deg}(\mathrm{n}=72$, range: 0.03 to $0.47 \mathrm{c} / \mathrm{deg})$ in the SCs, $0.06 \pm 0.02 \mathrm{c} / \mathrm{deg}(\mathrm{n}=99$, range: 0.025 to $0.3 \mathrm{c} / \mathrm{deg})$ in the $\mathrm{SCi}$, $0.05 \pm 0.04 \mathrm{c} / \mathrm{deg}(\mathrm{n}=105$, range: 0.025 to $0.24 \mathrm{c} / \mathrm{deg})$ in the $\mathrm{Sg}$ and $0.05 \pm 0.03 \mathrm{c} / \mathrm{deg}(\mathrm{n}=$ 89, range: 0.025 to $0.18 \mathrm{c} / \mathrm{deg}$ ) in the $\mathrm{CN}$. The ANOVA showed significant difference among the optimal spatial frequencies of the investigated structures $(\mathrm{p}=0.0004, \mathrm{~F}(3$, $374)=16.376)$. The post-hoc analysis revealed that the mean optimal spatial frequency measured in the SCs was significantly higher than that of the SCi $(\mathrm{p}=0.000019)$, the $\mathrm{Sg}$ $(\mathrm{p}=0.000008)$ and the $\mathrm{CN}(\mathrm{p}=0.000008)$. In contrast, no significant difference $(\mathrm{p}>$ 0.05) among the optimal spatial frequencies of the $\mathrm{SCi}$, the $\mathrm{Sg}$ and the $\mathrm{CN}$ could be justified.

Further investigation of the neurons having spatial band-pass characteristics showed (Figure $3 \mathrm{~B}$ ) that the mean spatial frequency bandwidth was $1.84 \pm 0.15$ octaves (n $=35$, range: 0.39 to 3.60 octaves) in the SCs, $1.06 \pm 0.56$ octaves $(n=24$, range: 0.1 to 2.18 octaves) in the $\mathrm{SCi}, 1.07 \pm 0.69$ octaves ( $\mathrm{n}=41$, range: 0.11 to 2.81 octaves) in the $\mathrm{Sg}$ and $1.31 \pm 0.76$ octaves ( $\mathrm{n}=15$, range: 0.37 to 3.0 octaves) in the $\mathrm{CN}$. In the same way as in case of the optimal spatial frequency, a significant difference among the investigated structures was proved by summarized statistical analysis of the spatial frequency bandwidths $(p=0.00008, F(4,236)=6.3167)$. The post-hoc analysis showed that the spatial frequency bandwidth of the band-pass neurons in the SCs was significantly higher than that of the SCi $(p=0.003766)$, the $\operatorname{Sg}(p=0.000037)$ and the $\mathrm{CN}(\mathrm{p}=0.006262)$. On the contrary, no significant difference $(\mathrm{p}>0.05)$ among the spatial frequency bandwidths of the $\mathrm{SCi}$, the $\mathrm{Sg}$ and the $\mathrm{CN}$ was found. 
A

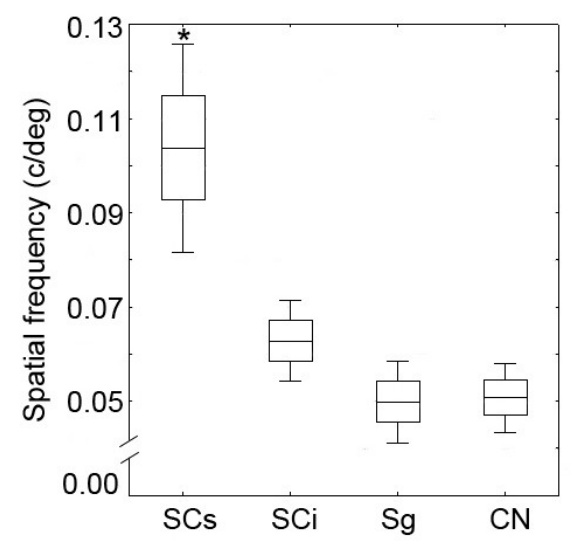

B

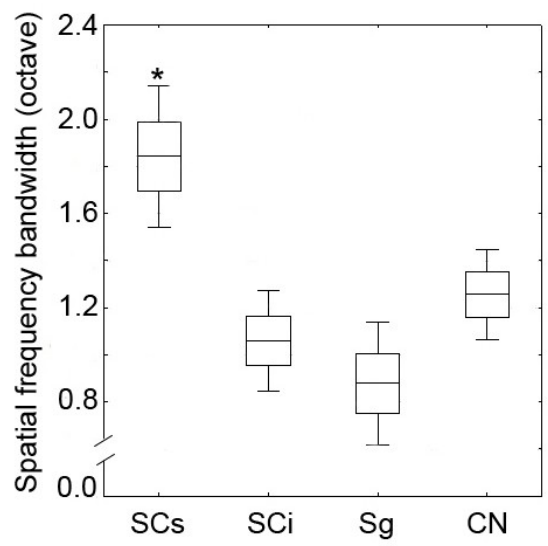

Figure 3. Statistical comparisons of the spatial visual properties in the ascending tectofugal system. A and $\mathrm{B}$ shows the comparison between the mean optimal spatial frequencies and between the spatial frequency bandwidth, respectively.

The mean optimal temporal frequency was $6.84 \pm 0.71 \mathrm{~Hz}(\mathrm{n}=62$, range: 0.74 to $26.41 \mathrm{~Hz})$ in case of the SCs, $9.06 \pm 5.49 \mathrm{~Hz}(\mathrm{n}=99$, range: 1.71 to $31.93 \mathrm{~Hz})$ in the $\mathrm{SCi}$, $8.53 \pm 4.43 \mathrm{~Hz}(\mathrm{n}=105$, range: 0.07 to $26.41 \mathrm{~Hz})$ in the $\mathrm{Sg}$ and $10.6 \pm 4.8 \mathrm{~Hz}(\mathrm{n}=89$, range: 4.6 to $27.6 \mathrm{~Hz}$ ) in the $\mathrm{CN}$ (Figure $4 \mathrm{~A}$ ). According to the result of the summarized statistical analysis of the investigated structures a significant difference among the optimal temporal frequencies could be confirmed $(p=0.03980, F(3,314)=2.8067)$. The post-hoc analysis proved that the mean optimal temporal frequency in the SCs was significantly lower than that of the SCi $(p=0.023064)$, the Sg $(p=0.0123403)$ and the $\mathrm{CN}(\mathrm{p}=0.0384452)$. On the other hand, we found no significant difference $(\mathrm{p}>0.05)$ among the optimal temporal frequencies of the SCi, the Sg and the CN.

Additional analysis of the neuronal responses revealed (Figure $4 \mathrm{~B}$ ) that the mean temporal frequency bandwidth of the neurons having temporal band-pass characteristics was $2.38 \pm 0.22$ octaves ( $n=42$, range: 0.40 to 5.90 octaves $)$ in the SCs, $2.32 \pm 0.97$ octaves ( $n=48$, range 0.25 to 4.29 octaves) in the $\mathrm{SCi}, 1.66 \pm 1.37$ octaves ( $\mathrm{n}=73$, range: 0.03 to 7.91 octaves) in the $\mathrm{Sg}$ and $1.38 \pm 1.0$ octaves ( $\mathrm{n}=55$, range: 0.09 to 5.36 octaves $)$ in the $\mathrm{CN}$. Correspondingly to the optimal temporal frequency, a significant difference among the investigated structures was revealed by the summarized statistical analysis of the 
temporal frequency bandwidths $(\mathrm{p}=0.00000, \mathrm{~F}(4,307)=13.797)$. The post-hoc analysis showed that the temporal frequency tuning bandwidth of the neurons in the SCs and the SCi was not significantly different, but the temporal frequency bandwidths of both the SCs and the SCi neurons were significantly higher than that of the neurons in the $\operatorname{Sg}(p=$ 0.000024 in case of the SCs and $p=0.000024$ in case of the SCi) and the CN (p = 0.022821 in case of the SCs and $p=0.029981$ in case of the SCi). No significant difference $(\mathrm{p}>0.05)$ between the temporal frequency bandwidths of the Sg and the CN could be justified.

A

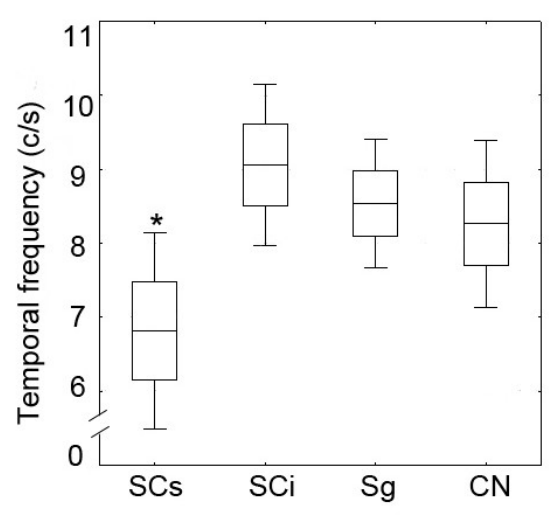

$B$

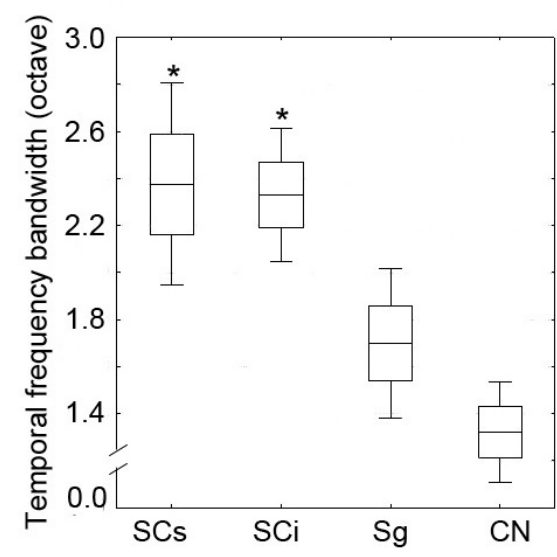

Figure 4. Statistical comparisons of the temporal visual properties in the ascending tectofugal system. $\mathrm{A}$ and $\mathrm{B}$ shows the comparison between the mean optimal temporal frequencies and between the temporal frequency bandwidth, respectively.

CROSS-CORRELATION ANALYSIS BETWEEN THE CAUDATE NUCLEUS AND THE SUPRAGENICULATE NUCLEUS

Altogether 138 visually active neurons were recorded with stable spontaneous activity from the $\mathrm{Sg}$ and 142 from the $\mathrm{CN}$. From these neuron pools we could form 283 simultaneously recorded Sg-CN cell-pairs the synchronization of which has been investigated.

CORRELATION DURING SPONTANEOUS ACTIVITY

To find out about the baseline synchronization without the presence of visual stimuli, we analysed cross-correlation during the period of black blank screen background 
presence in the visual field. On the whole, 26 pairs $(9.19 \%)$ showed significant correlation, the residual 257 pairs $(90.81 \%)$ were not significantly correlated. All the detected interactions were excitatory, indicated by a positive peak on the crosscorrelogram. The most intriguing finding of the present study is that it could not be determined unambiguously whether $\mathrm{Sg}$ or $\mathrm{CN}$ is the master structure in the information processing pathway. In 13 cases (50\%) the peak on the cross-correlogram, with a mean timelag of $6.8 \pm 2.52 \mathrm{~ms}$, indicates that $\mathrm{Sg}$ leads $\mathrm{CN}$ (Figure $5 \mathrm{~A}, \mathrm{~B}$ ). On the other hand in 11 cases $(42.31 \%) \mathrm{CN}$ seems to be the information transmitter, and $\mathrm{Sg}$ is the receiver, the mean timelag being $5.7 \pm 2.10 \mathrm{~ms}$ (Figure $3 \mathrm{C}$, D). Moreover, in two cases $(7.69 \%)$ the peak appeared with $0 \mathrm{~ms}$ timelag ${ }^{1}$, which indicates that the two structures were simultaneously activated.
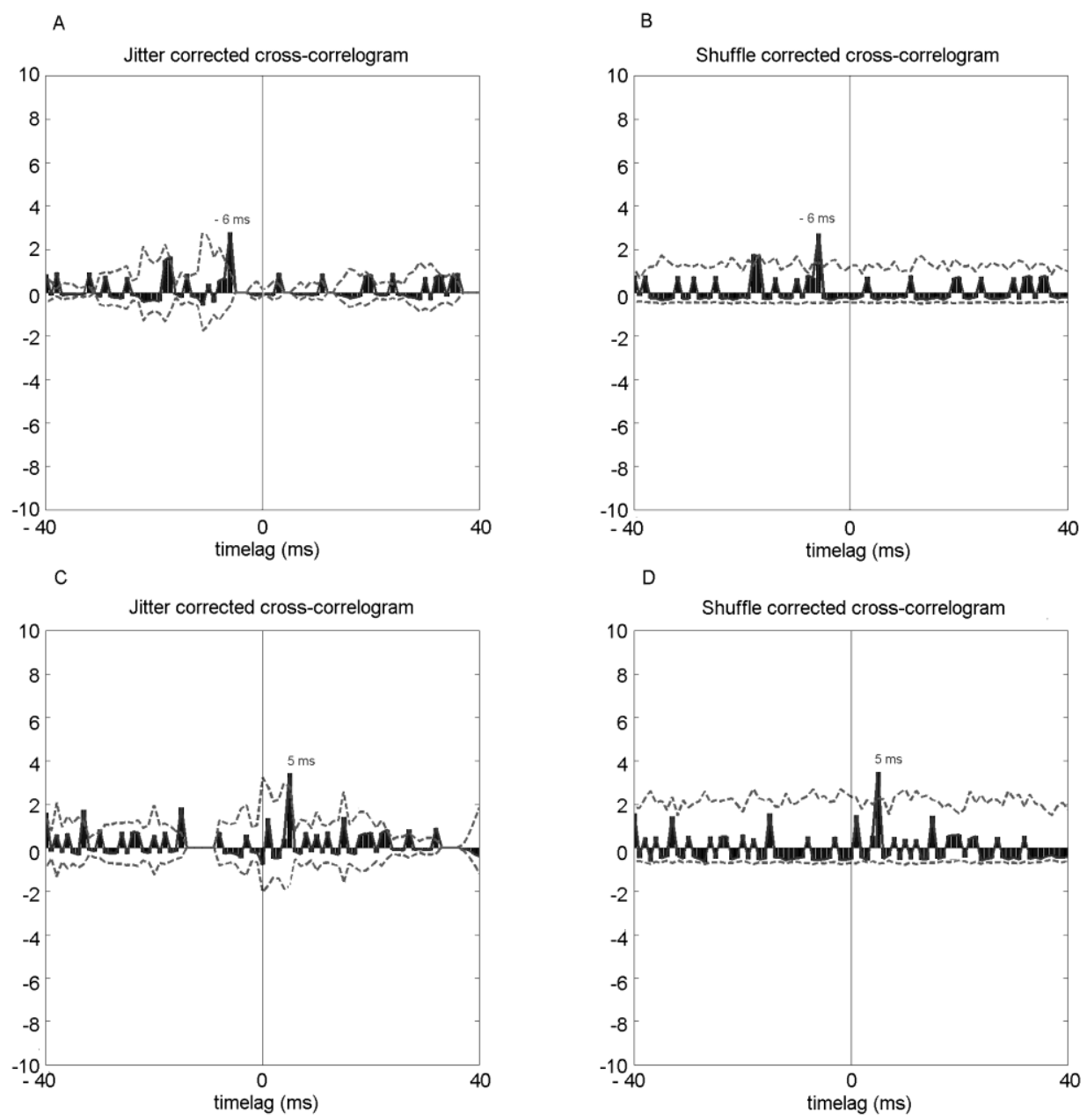

$10 \mathrm{~ms}$ timebin $=0+/-1 \mathrm{~ms}-$ because of the $1 \mathrm{~ms}$ bin resolution this range means synchronisation 
Figure 5. Cross-correlograms during spontaneous activity. A and B demonstrate examples of correlated spontaneous neuronal activity, when the suprageniculate nucleus $(\mathrm{Sg})$ was the sender structure, while $\mathrm{C}$ and D represent examples of the caudate nucleus $(\mathrm{CN})$ firing earlier. A and $\mathrm{C}$ show the jitter corrected crosscorrelograms, while B and D show the shuffle corrected cross-correlograms. The corrected crosscorrelograms are indicated with a thick black line, the gray dashed line signifies the statistical acceptance band. The vertical black line indicates the $0 \mathrm{~ms}$ timelag. The abscissa denotes the timelag (ms) and the ordinate represents the cross-correlation function.

CORRELATION DURING STATIC RANDOM DOTS STIMULATION

When we analysed the cross-correlograms during the stationary random dot stimulation, we found significant correlation in 19 pairs $(6.71 \%)$; all of them indicated excitatory interaction. In 8 cases $(42.11 \%$ ) the $\mathrm{Sg}$ (mean timelag $5 \pm 2.56 \mathrm{~ms}$, Figure 6 ), in 7 cases $(36.84 \%) \mathrm{CN}$ (mean timelag $=5.86 \pm 2.91 \mathrm{~ms}$, Figure 7) seemed to be the preceding structure, and we could detect simultaneous activation with a timelag of $0 \mathrm{~ms}$ for this type of stimuli in 4 cases (21.05\%). All the pairs which showed significant crosscorrelation were different from those which showed significant interaction during the spontaneous period. Thus it seems that there are different subpopulations among the directly connected Sg-CN neuronal pairs. Visual stimulation can either synchronize the neuronal activity between the $\mathrm{Sg}$ and $\mathrm{CN}$ (those 19 neuron pairs that showed no significant cross-correlation in the analysis of spontaneous activity but showed crosscorrelation during static visual stimulation) or can also desynchronize the activity of the $\mathrm{Sg}$ and $\mathrm{CN}$ neurons (those $26 \mathrm{Sg}-\mathrm{NC}$ neuron pairs which showed cross-correlated spontaneous activity but no cross-correlated activity to static visual stimulation). 

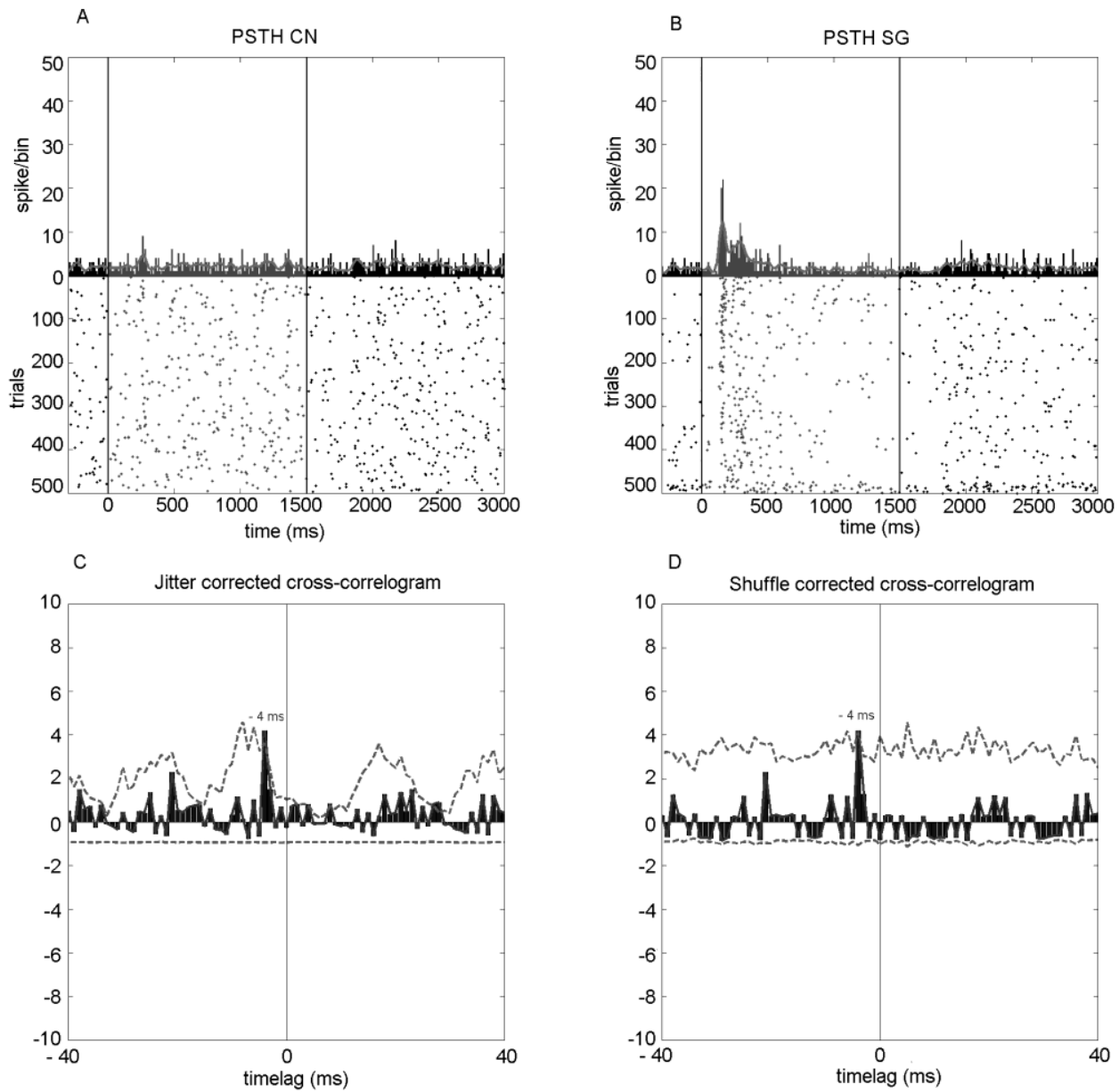

Figure 6. Cross-correlograms during static random dot stimulation, when the Sg activated earlier.

Part A shows the peristimulus time histogram (PSTH) and a raster plot of a CN neuron, while B shows the PSTH and the raster plot of the simultaneously recorded Sg neuron. In both neurons, increase of firing rate was observed during static visual stimulation. The gray areas represent the investigated epoch of the trials which were used in the cross-correlation analysis. The black lines indicate the beginning of the stimuli (the left one is the starting of the static dots stimulus, the right one is the beginning of the randomly moving dots stimulus). C shows the jitter corrected cross-correlogram and D demonstrates the shuffle corrected one. The rest of the conventions are the same as on Figure 5. 

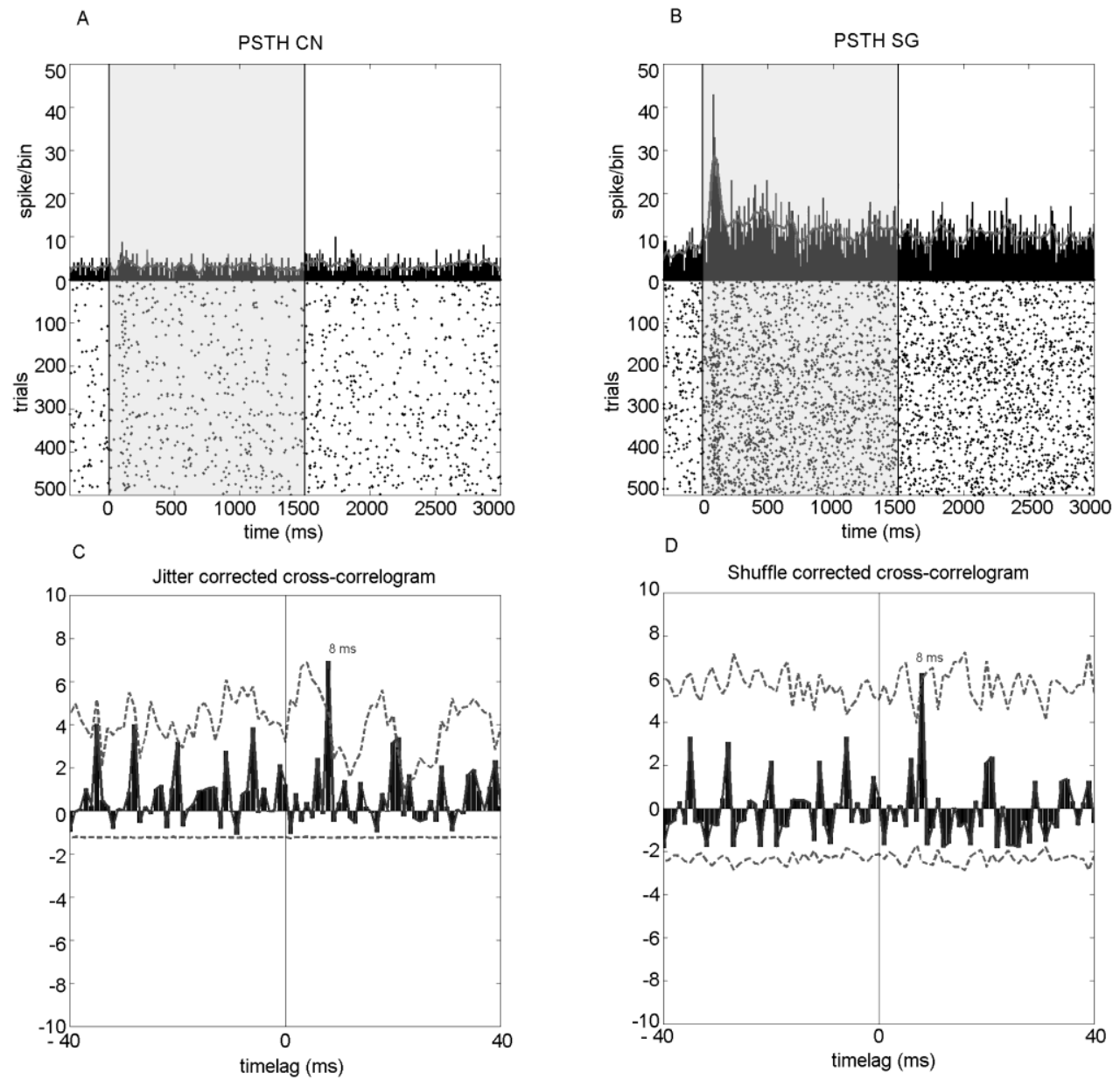

Figure 7. Cross-correlograms during static random dots stimuli, when the $\mathrm{CN}$ activated earlier. In both neurons, increase of firing rate was observed during static visual stimulation. The conventions are the same as on Figure 6.

\section{CORRELATION DURING RANDOMLY MOVING DOTS STIMULATION}

We also calculated the cross-correlation between the two structures during moving random dots stimulation. In 21 cases $(7.42 \%)$ we found significant excitatory interaction between the two structures, and no inhibitory interaction was indicated. Sg seemed to be the preceding structure in 10 cases $(47.62 \%$, Figure 8$)$, with a mean timelag of $5.7 \pm 2.8$ $\mathrm{ms}$, and $\mathrm{CN}$ was indicated to be preceding in 8 cases $(38.10 \%$, Figure 9$)$, with a mean timelag of $4.25 \pm 1.8 \mathrm{~ms}$. Simultaneous activation during the randomly moving dots stimulus could be detected in 3 cases (14.29\%). None of these $21 \mathrm{Sg}-\mathrm{CN}$ neuron pairs showed significantly cross-correlatated spontaneous activity, however, in 3 of the 21 
cases we found significant excitatory interaction to both static and moving dot stimulations.
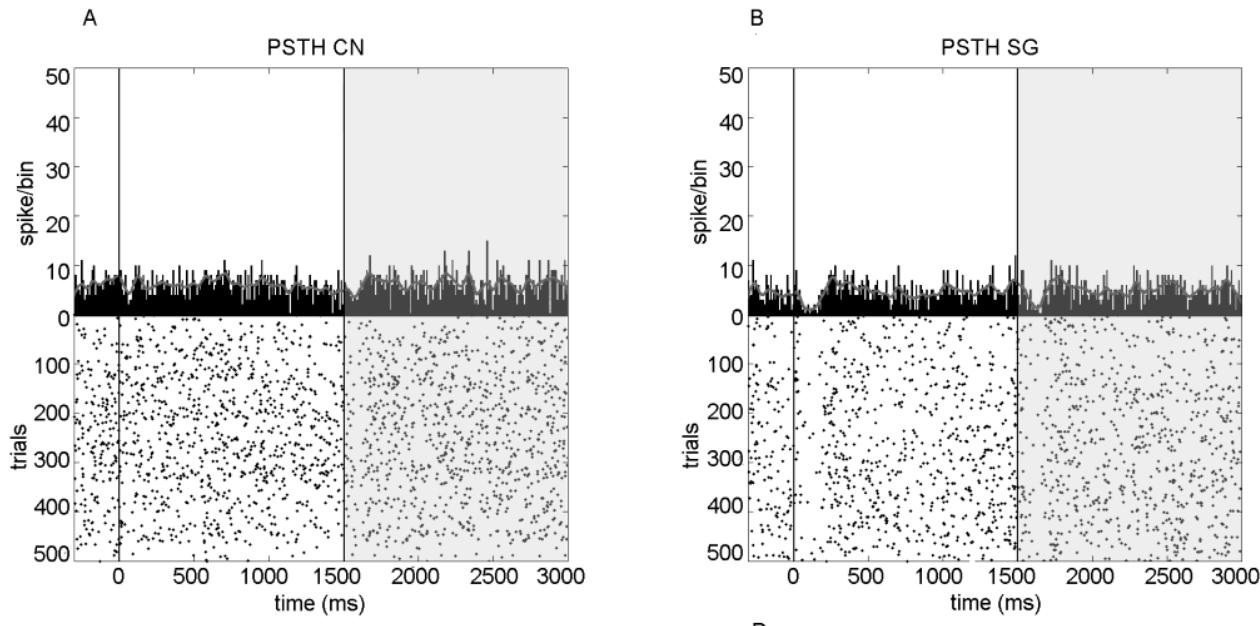

$c$

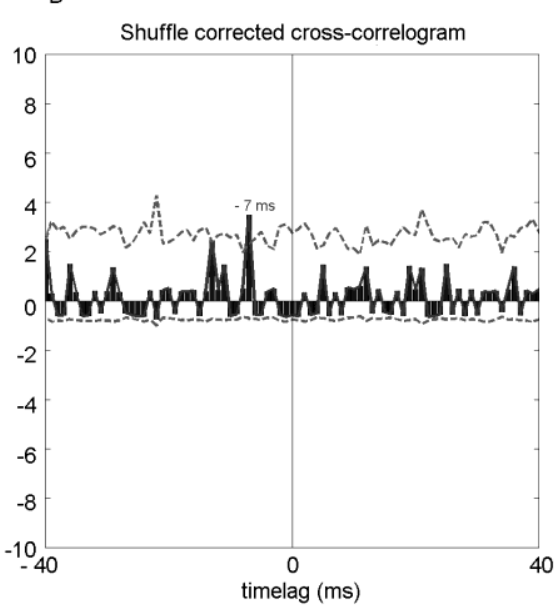

Figure 8. Cross-correlograms during randomly moving dots stimuli when the Sg activated earlier. In both neurons, decrease of firing rate was observed at the onset of movement. The conventions are the same as on Figure 6. 

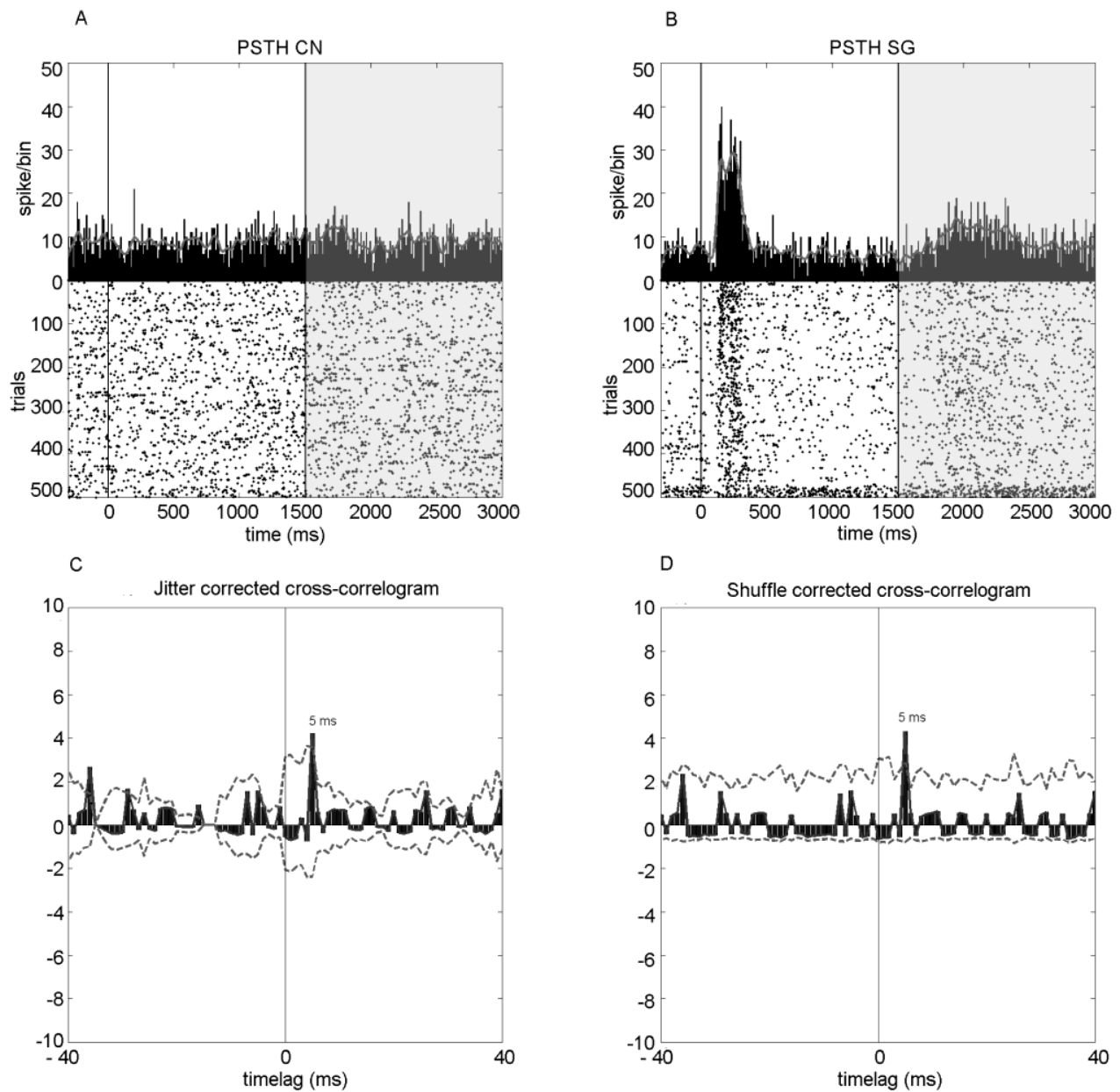

Figure 9. Cross-correlograms during randomly moving dots stimuli when the $\mathrm{CN}$ activated earlier. In both neurons, increase of firing rate was observed during the movement. The conventions are the same as on Figure 6.

ANALYSIS OF THE VISUAL ONSET RESPONSE LATENCIES IN THE SG AND THE CN

Beside the cross-correlation analysis, we also measured the response onset latencies in the $\mathrm{Sg}$ and $\mathrm{CN}$ for the onset of static random dots stimulation and for randomly moving dots. In the case of both $\mathrm{CN}$ and $\mathrm{Sg}$, the distribution of measured latencies for static visual random dot stimulation was non-normal (Shapiro-Wilk test: $\mathrm{p}<$ $0.001, \mathrm{n}=107$ for $\mathrm{Sg}$ and $\mathrm{p}=0.012, \mathrm{n}=72$ for $\mathrm{CN}$ ). The median latency for $\mathrm{Sg}$ was 80 $\mathrm{ms}(\min =20 \mathrm{~ms}, \max =210 \mathrm{~ms}$, Figure $8 \mathrm{~A})$, while the median latency for $\mathrm{CN}$ was 100 
$\mathrm{ms}(\min =20 \mathrm{~ms}, \max =200 \mathrm{~ms}$, Figure $8 \mathrm{~B})$. We found no significant difference between latencies within the two groups (Kolmogorov-Smirnov test, $p=0.556$ ). The distributions of latencies to randomly moving dot stimuli were non-normal in both groups (Shapiro-Wilk test: $\mathrm{p}<0.001, \mathrm{n}=94$, median $=60 \mathrm{~ms}$, $\min =20 \mathrm{~ms}, \max =200 \mathrm{~ms}$ for $\mathrm{Sg}, \mathrm{p}=0.001, \mathrm{n}=82$, median $=80 \mathrm{~ms}, \min =20 \mathrm{~ms}, \max =200 \mathrm{~ms}$ for $\mathrm{CN}$ ). There was no significant difference between the response onset latencies to moving visual stimulation of the CN and Sg (Kolmogorov-Smirnov test: $\mathrm{p}=0.425)$.
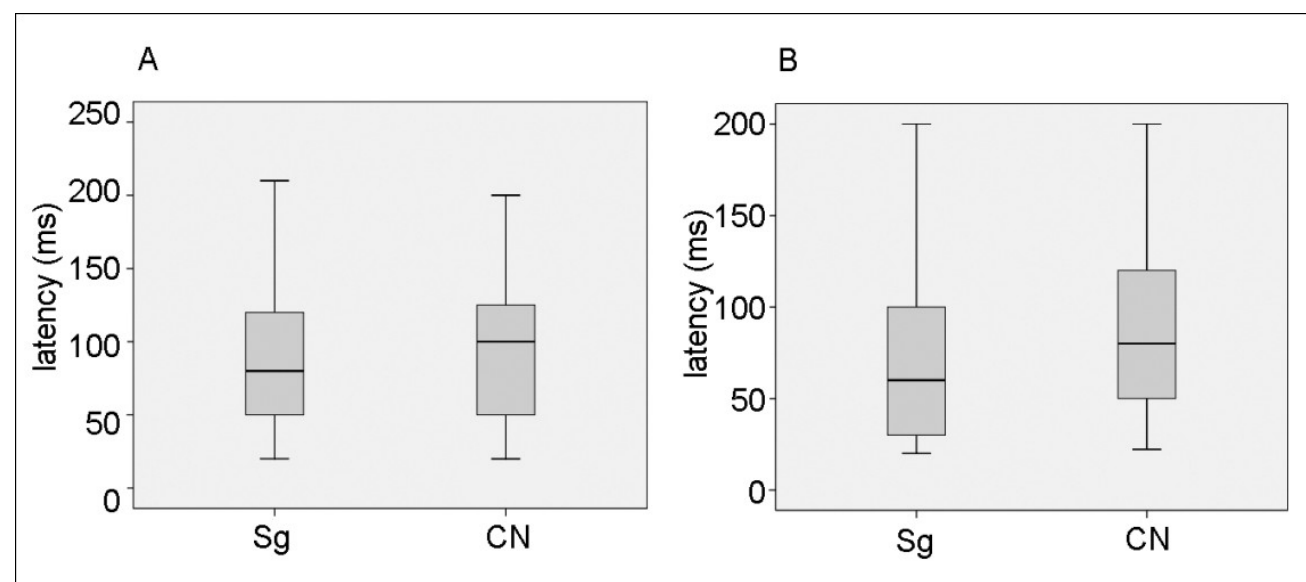

Figure 10. Visual response onset latencies during static and moving visual stimulation. Part A shows the distribution of latency values of the $\mathrm{Sg}$ and $\mathrm{CN}$ units upon static visual stimulation, while the diagrams of part B represent the response onset latencies upon moving visual stimulation. The box-plot diagrams show the descriptive statistics of the latencies of the static random dots stimulus. The median, the $25 \%$ and the $75 \%$ percentiles, the minimum and maximum values are indicated for both structures. Note that there is no significant difference between the latencies of the $\mathrm{Sg}$ and the $\mathrm{CN}$ neurons.

We also examined the latencies between the recorded $\mathrm{CN}-\mathrm{Sg}$ neuron pairs. We observed latency differences during static stimulation for 165 pairs. We found that during static visual stimulation in $49.70 \%$ (82 pairs) the latency was shorter in $\mathrm{Sg}$, in $46.67 \%$ (77 pairs) in $\mathrm{CN}$, and in $3.64 \%$ (6 pairs) there was no difference between the latencies. In the moving dot condition we examined 150 pairs and we found that in $38.67 \%$ (58 pairs) the latency was shorter in the $\mathrm{Sg}$, in $54 \%$ (81 pairs) in the $\mathrm{CN}$, and in $7.33 \%$ (11 pairs) there was no difference in latency. 
Both morphological and physiological studies have suggested that separate geniculate and extrageniculate visual systems exist in the feline brain. The lateral geniculate nucleus (LGN) is thought to be the most important central structure receiving inputs from the retina. Nevertheless, beside the LGN, altogether nine subcortical structures have been found that receive afferents directly from the retina (Rosenquist, 1985). Of these structures, during the past 25 years most of the research interest was focused on the SC and the tectal pathway.

Scientific interest was sparked when Otto Creutzfeldt and Lennart Mucke serendipitously discovered the anterior ectosylvian sulcus (AES) (Mucke et al., 1982) and initiated experiments to reveal the visual properties of this new area. It has to be noted that in the meantime Olson and Graybiel also detected the existence of the anterior ectosylvian visual area (AEV) in the same way (Olson \& Graybiel, 1983; 1987). The morphological experiments confirmed the tectal source of visual information towards the AES cortex. Hence, this area now seems to be the only cortical visual area that is provided with visual afferentation entirely bypassing the lateral geniculate complex (Rosenquist, 1985; Norita et al., 1991; Hoshino et al., 2009b). The AEV receives thalamic afferents mainly from the $\mathrm{Sg}$, while a smaller fraction of the afferentation comes from the medial part of the posterior lateral nucleus (LPm) (Olson \& Graybiel, 1987). The source of the cortical afferentation to the AEV is mainly the PMLS (Norita et al., 1986; Miceli et al., 1985). The predominant targets of efferentation of the visual neurons along the AEV are the Sg and the intermediate and deep layers of the SC, although it sends visual efferents to the PMLS, to the frontal visual areas (lower bank of the cruciate sulcus and the lower lateral side of the frontal part of the feline brain), to the amygdala and other cortical and subcortical structures, outside of the lateral geniculate complex and the A17 region (Norita et al., 1986).

The substantial corticothalamic connectivity directed the attention to the Sg. This nucleus of the posterior thalamus has earlier been paid less attention to in morphological and physiological analysis. Anatomical tracing experiments proved that there is a 
noteworthy convergence of inputs from a wide anteroposterior and mediolateral aspect of the SCi and deep layers of the SC (SCd) to the neurons in the Sg (Katoh \& Benedek, 1995). In fluorescein double-staining experiments the existence of collicular neurons sending bifurcating axons towards the ipsilateral and also the contralateral $\mathrm{Sg}$ was proved (Katoh et al, 1995). A substantial projection was traced from the ventral $\mathrm{Sg}$ to the posterior dorsolateral part of the CN (Hoshino et al., 2009a). This finding extended the observations to the $\mathrm{CN}$, known to be directly involved in visuomotor control.

The summarized results showed that the ascending tectal axons carrying visual information constitute a fiber pathway linking the mesencephalon with the dorsal thalamus and then with a number of telencephalic centers. The neurons in this pathway exhibit unique physiological properties, which in no way resemble those described in the geniculostriate pathway. The same receptive field properties have been found in neurons along the $\mathrm{AES}$, the $\mathrm{SCi}$, the $\mathrm{SCd}$, the $\mathrm{Sg}$ and the posterior dorso-lateral part of the $\mathrm{CN}$ (Benedek et al, 1988; 1997). The most intriguing finding was the absolute absence of retinotopic organization, in contrast with the impressive retinotopy in the geniculostriate pathway (Tusa et al., 1978). Receptive fields consistently included the area centralis and extended practically over the entire visual field of the corresponding eye, not only in the $\mathrm{AEV}$, but in all the regions found in this pathway. A striking physiological characteristic of these neurons (i.e., in the $\mathrm{AEV}$, the $\mathrm{SCi}$, the $\mathrm{SCd}$ the $\mathrm{Sg}$ and the $\mathrm{CN}$ ) is their overwhelming sensitivity to movement in the receptive field. The neurons respond optimally to small stimuli moving at high velocities in a specific direction within the huge receptive fields. High directional sensitivity, together with the preference for a high stimulus speed was a characteristic that turned out to be similarly valid for the cells in the $\mathrm{SC}$, which is evidently the main source of visual information for this pathway (Stein \& Meredith, 1993). The neurons along the extrageniculate visual pathway seemed not to be sensitive to the orientation or shape of the stimuli. This supports our concept that the receptive field properties make these cells serve as "motion" or "novelty" detectors.

Visual information processing depends critically upon the integration of spatial and temporal information. The sinusoidally modulated grating is an elementary component of the visual scene in the sense that any two-dimensional visual object can be represented by an appropriate combination of these gratings (De Valois et al. 1979; Pinter \& Harris, 1981). Responses of neurons to drifting gratings of different spatial and 
temporal frequencies can be interpreted in terms of the dimensions and distribution of spatially and temporally summed excitatory and inhibitory components within their receptive fields (Enroth-Cugell \& Robson, 1966; Zumbroich et al., 1988). Thus, the discussion of the spatiotemporal filter properties of neurons in the ascending tectofugal system may contribute to an understanding of the role of the system in visual information processing and the related sensory-motor actions.

\section{SPATIO-TEMPORAL VISUAL RESPONSE PROPERTIES IN THE ASCENDING} TECTOFUGAL SYSTEM

At the first stage of our studies we sought to compare the spatio-temporal spectral receptive field properties of different subcortical structures, i.e. $\mathrm{SCs}, \mathrm{SCi}, \mathrm{Sg}$ and $\mathrm{CN}$ of the ascending tectofugal visual system. Earlier studies of our group on the $\mathrm{Sg}$ and the $\mathrm{CN}$, and earlier studies of our group and other research groups on the SCs and SCi established that the SCs, SCi, Sg and $\mathrm{CN}$ neurons respond optimally to low spatial frequencies, and exhibit low spatial resolution and low-pass spatial tuning. Moreover, not only the spatial but also the temporal frequency properties of the $\mathrm{SCs}, \mathrm{SCi}, \mathrm{Sg}$ and $\mathrm{CN}$ are similar. The neurons responded optimally to high temporal frequencies, had high temporal frequency cut-off values and narrow temporal frequency tuning (Nagy et al., 2008; Paróczy et al., 2006; Waleszczyk et al., 2007; Márkus et al., 2009; Pinter \& Harris, 1981; Mimeault et al., 2004). These findings indicate that these neurons act as good spatio-temporal filters in the low spatial and high temporal frequency domain. The statistical analysis revealed that the spatio-temporal response properties of the SCs were significantly different from not only those of the SCi but the Sg and CN. SCs neurons prefer lower spatial and higher temporal frequencies than $\mathrm{SCi}, \mathrm{Sg}$ and $\mathrm{CN}$ neurons. The spatial frequency tuning of the SCs is significant broader than that of the $\mathrm{SCi}, \mathrm{Sg}$ and $\mathrm{CN}$. In contrast the $\mathrm{SCi}, \mathrm{Sg}$ and $\mathrm{CN}$ neurons showed statistically similar spatio-temporal response profiles. That is, $\mathrm{SCi}, \mathrm{Sg}$ and $\mathrm{CN}$ neurons prefer the same spatial and temporal frequencies and their spatial tuning is similarly narrow. This supports our hypothesis that the visually active $\mathrm{SCi}, \mathrm{Sg}$ and $\mathrm{CN}$ neurons form a homogeneous neuronal population, concerning their spatio-temporal response profiles.

According to our results, the SC seems not to be a uniform structure of the midbrain. As for the physiological differences, the SCs responds exclusively to visual 
stimuli, while the deeper layers are multisensory, processing auditory and somatosensory information as well (Meredith \& Stein, 1986). The SCs seems to play a role in the central processing of visual information (Stein \& Meredith, 1991), e.g. visual attention and orientation behavior (Sprague, 1991). The SCi and SCd are regarded as important structures for the control of saccadic eye movements (Wurtz \& Albano, 1980) and in cross-modal integration (Meredith \& Stein, 1986). Beside being a crucial part of the oculomotor system, these layers are involved in the control of head movements (Crowie \& Robinson, 1994; Freedman \& Sparks, 1997) and goal-directed arm movements (Werner et al., 1997). In addition to the anatomical, physiological and functional differences between SCs and SCi, the spatio-temporal properties of the SCs and SCi also show significant differences. Our results, together with earlier studies, suggest a functional relationship of the SCs to the geniculo-striate visual system, while the SCi is a part of the ascending tectofugal system (Harting et al. $2001 \mathrm{a}, \mathrm{b}$ ) that also provides visual information to the associative cortical areas along the AES (Nagy et al., 2003a) .

Similar spatio-temporal frequency profiles of the $\mathrm{SCi}, \mathrm{Sg}$ and the $\mathrm{CN}$ suggest a common role in visual information processing.

\section{ASSUMED ROLE OF THE ASCENDING TECTOFUGAL SYSTEM IN VISUAL MOTION DETECTION}

The low spatial and high temporal frequency preference of the cells in the ascending tectofugal system suggests that it is strongly dominated by $\mathrm{Y}$ and $\mathrm{W}$ signals, and contradicts a significant role of the X signal in this system (Paróczy et al., 2006; Wang et al., 1998). The ascending tectofugal visual system may be involved in novelty detection and motion perception. In human vision, all motion detectors extend over a wide range of spatial frequencies, but does not seem to play a major role at high spatial frequencies (Anderson \& Burr, 1985). All motion detectors are apparently fine-tuned for temporal and spatial frequencies (Anderson \& Burr, 1985), the narrow tuning being an aid for velocity detection and the analysis of the object in motion (Burr \& Ross, 1987a,b). It is suggested that neurons in the $\mathrm{SCi}, \mathrm{Sg}$ and $\mathrm{CN}$ with preferences for low spatial frequencies and with fine spatial and temporal tuning may have all the capacities necessary for perceiving rapid changes of the environment and the analysis of the velocity of movements. Thus, they may be regarded as possible anatomical and physiological 
correlates for the perception of self-motion. Therefore, we suggest that the ascending tectofugal system may play a role in detecting movements of the visual environment relative to the body, and thus it may participate in the adjustment of motor behaviour in response to environmental challenges.

\section{HOMOLOGY BETWEEN THE PRIMATE AND FELINE BRAIN REGARDING STRUCTURES TAKE PART IN VISUAL MOTION DETECTION}

Thorough investigations have been carried out during the last few decades to explore the neuronal background of motion detection in both primates and man. In the human brain, researchers found an area in the occipital cortex (V5/MT), which proved to be highly specialized for visual motion detection (Zeki et al., 1991). This area is the possible human homologue of the MT-MST area in the monkey brain, which has been in the focus of attention of researchers recently. The MT-MST area of the non-human primate brain has been proven to have anatomical connections with the areas V1, V2, V3 and V4, moreover, it has also direct input from the LGN (Fries, 1981; Yukie \& Iwai, 1981) and pulvinar (Standage, 1983) nuclei of the thalamus, bypassing the primary visual (striate) cortex, V1. The presence of visual fibers to MT bypassing V1 might as well provide a plausible explanation for the relatively intact motion sensitivity in patients after V1 damage (Weiskrantz, 1986).

Extensive efforts have been made to prove a direct projection from the LGN to the extrastriate cortex. A direct projection from the LGN to the MT has been reported as a result of few studies (Nassi \& Callaway, 2009; Fries, 1981; Yukie \& Iwai, 1981; Gross, 1991; Rodman et al., 1989; 1990). Indirect evidence for this direct thalamus-V5 connection is also available in man (Schoenfeld et al., 2002).

The PMLS area of the feline brain is generally considered to be a homologue of the MT, which is at a lower level than the MST in the visual motion pathway of primates (Zeki, 1974; Felleman \& Van Essen, 1991; Payne, 1993). As described in the introduction, the assumed analogy between the PLLS and the MST was not proven.

The possibility of the existence of an SC-pulvinar-MT pathway arose, and has been investigated several times, but finally Stepniewska et al. (1999) found that there are neurons in the medial nucleus of the inferior pulvinar - the major thalamic projection zone 
to the MT - that receive direct input from the SC. However, the functional role and the significance of this pathway in primates is not clear. We argue that the SC-pulvinar-MT tecto-thalamo-cortical pathway in the primate is a good candidate to be the primate homologue of the ascending tecto-thalamo (LM-Sg, LP-Pul)-cortical (AES cortex, LS areas) visual system in the feline brain.

\section{NEURONAL NETWORKS AND FUNCTIONAL COOPERTION WITHIN THE} ASCENDING TECTOFUGAL SYSTEM

The gain an overall knowledge about the function of a system, it is not enough to have information about the function of the different elements within the system but the knowledge of interactions and cooperation between the structures is essential as well. Therefore, during the last decades more and more interest has been focused on the neuronal networks, and the investigation of neuronal interaction. With the help of these newly investigated features we are able to get a deeper knowledge about the exact activity of the central nervous system.

\section{CORRELATED ACTIVITY OF THE SG-CN NEURON PAIRS}

In order to test the hypothesis that the activity of $\mathrm{CN}$ is modulated by the input originating in the ascending tectofugal system, we recorded neuronal activity simultaneously from Sg and CN (Harting et al., 2001) of the feline brain. We analysed the temporal interactions between these structures in detail, using cross-correlation methods, and provided the first piece of direct evidence on the functional connection between $\mathrm{Sg}$ and $\mathrm{CN}$.

First, we analysed the coupling of the spontaneous activity of $\mathrm{Sg}$ and $\mathrm{CN}$. We found that about $9 \%$ of the analyzed $\mathrm{Sg}-\mathrm{CN}$ neuron pairs showed significant crosscorrelated spontaneous activity. All the detected interactions were excitatory, indicated by a positive peak on the cross-correlogram. We found no negative correlations at all. However, there is a general agreement in the literature that inhibitory interactions (indicated by negative correlations) are much more difficult to detect by correlation analyses than excitatory ones (Aersten and Gerstein, 1985; Melssen and Epping, 1987). In order to check the effect of visual stimulation on the synchronization or desynchronization of the activity of $\mathrm{Sg}$ and $\mathrm{CN}$, we also analysed the activity of the same 
Sg-CN neuron pairs in response to static and dynamic visual stimulation. About 7-7\% of the investigated $\mathrm{Sg}-\mathrm{CN}$ neuron pairs exhibited cross-correlated activity during static and dynamic visual stimulation, respectively. Interestingly, we found no overlap between the neuron pairs that showed cross-correlated spontaneous activity and the neuron pairs that were synchronized during visual stimulation. It means that at least 2 functional groups might be differentiated between among the correlated Sg-CN neuron pairs. Neuron pairs of the first group showed significant cross-correlated spontaneous activity. On one hand, visual stimulation desynchronized the activity of the $\mathrm{Sg}$ and the $\mathrm{CN}$. Similar results were reported by de Oliveira et al (1997). They found that existing positive correlations between neurons in the MT were reduced upon visual stimulation. However, they did not find that the proper stimuli desynchronize the previously synchronized activities, rather, in most cases, the spontaneous correlation weakened during stimulation. (A possible explanation for this difference is that the statistical acceptance band construction was different from ours.) On the other hand, visual stimulation could also synchronize the activity of some of the neuron pairs. In this group those $\mathrm{Sg}-\mathrm{CN}$ pairs belong where we did not find any cross correlated spontaneous activity but the visual stimulation coupled the activity of the $\mathrm{Sg}$ and the $\mathrm{CN}$. Thus, visual stimulation could synchronize, and - by other neuron pairs - desynchronize the activities of $\mathrm{CN}$ and $\mathrm{Sg}$.

An interesting finding of the present study is that we could not determine unambiguously whether $\mathrm{Sg}$ or $\mathrm{CN}$ is the earlier stage of the information processing pathway. In about half of the cross-correlated $\mathrm{Sg}-\mathrm{CN}$ pairs $\mathrm{Sg}$ was activated earlier, which indicates that it is the sender structure, and it sends the information toward $\mathrm{CN}$. This result is in agreement with recent data (Takada et al., 1985; Hu and Jayaraman, 1986; Harting et al., 2001; Hoshino et al., 2009b). On the other hand, in about $42 \%$ of the cross-correlated $\mathrm{Sg}-\mathrm{CN}$ neuron pairs, $\mathrm{CN}$ activated earlier. In these cases $\mathrm{CN}$ seems to be the sender, and it is supposed to be the information transmitter structure toward Sg. The remaining $8 \%$ of the cross-correlated neuron pairs activated simultaneously with a timelag of $0 \mathrm{~ms}$. It was suggested earlier (Gochin et al., 1991) that simultaneous activation is signified by a wide peak, with a center at $0 \mathrm{~ms}$ timelag on the crosscorrelogram, and not by a narrow peak, as is the case here. The only considerable explanation for this type of peak should be that one neuron sent information toward both structures, and theoretically this is satisfying indeed, as neurons with bifurcating axons 
are typical in the ascending tectofugal system (Katoh et al., 2000; Hoshino et al., 2004). The short, few-millisecond (never longer than $10 \mathrm{~ms}$ ) time lag between the crosscorrelated activity of $\mathrm{CN}$ and $\mathrm{Sg}$ suggests a short direct pathway with most probably one or sometimes 2 synapses (Alonso and Martinez, 1998), or the possible existence of weak synapses along the pathway moreover it could be the consequence of indirect connection. As for the cases where we found 0 ms time lag between the two structures, we argue that a common input might also exist, comprising of parallel pathways synchronizing them (Nowak et al., 1995). The source of this common input might be the visual associative cortical areas, i.e. the anterior ectosylvian cortex or the lateral suprasylvian areas of the brain (Norita et al, 1986). Based on our results, we constructed a schematic drawing about the ascending tectofugal system, which summarizes the assumed pathways of visual information flow between the $\mathrm{Sg}$ of the posterior thalamus and the $\mathrm{CN}$ (Figure 11).

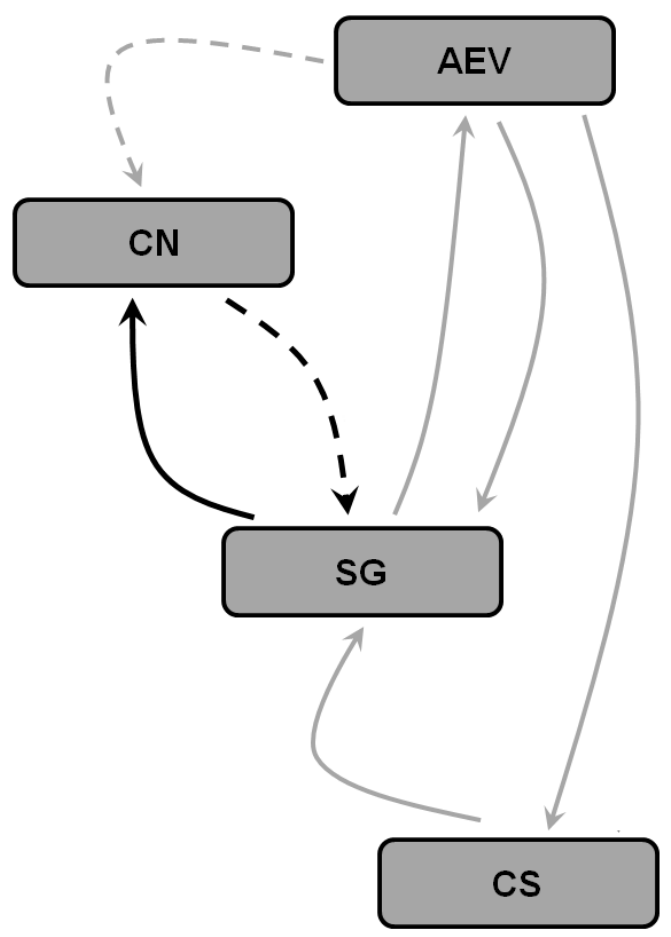

Figure 11. Flow of visual information within the ascending tectofugal system. Connections and information transmission routes are indicated by arrows; dashed lines indicate proposed routes. Abbreviations: AEV: anterior ectosylvian visual area, $\mathrm{CN}$ : caudate nucleus, CS: colliculus superior, SG: suprageniculate nucleus 
LATENCY ANALYSIS OF VISUAL RESPONSE ONSET IN THE SG AND CN

Further indirect evidence, which could give support to the temporal interaction between the two structures and which may provide additional information on the information flow, is the analysis of the neuronal response onset latencies.

In order to perform an objective statistical analysis of the onset response latencies, we used an automated method, the double sliding window method, developed in our laboratory (Berényi et al., 2007). We found no difference between the shortest latency values of the thalamic and the $\mathrm{CN}$ single-units. Both structures responded to visual motion with a minimum latency of $20 \mathrm{~ms}$. Furthermore, the mean response latency of $\mathrm{Sg}$ units is statistically not different from that of the $\mathrm{CN}$ neurons. The investigation of the neuronal response onset latencies of the simultaneously recorded $\mathrm{Sg}$ and $\mathrm{CN}$ neuron pairs revealed no precedence of either of the structures. In about half of the cases, Sg was activated earlier, while in the other half of the $\mathrm{Sg}-\mathrm{CN}$ neuron pairs, $\mathrm{CN}$ showed shorter onset response latency. The potential existence of a bidirectional information flow between the posterior thalamus and the forebrain is in line with the findings of Ouelette and Casanova (2006), where the time relation of the lateral posterior-pulvinar complex of the posterior thalamus and the visual cortical areas were investigated. Similarly, bidirectional information flow was described between $\mathrm{Sg}$ and the anterior ectosylvian visual area (Eördegh et al., 2005).

Based on our results from cross-correlation and latency analysis we argue that either a monosynaptic bidirectional direct connection exists between the $\mathrm{Sg}$ of the posterior thalamus and the $\mathrm{CN}$ (cross-correlated neuron pairs with a time lag of some ms), or a common input (cross-correlated neuron pair with $0 \mathrm{~ms}$ time lag) comprising of parallel pathways synchronizes their activity. 


\section{CONCLUSIONS}

Our results demonstrate that neurons within all investigated subcortical structures of the ascending tectofugal system (namely $\mathrm{Sg}, \mathrm{SCi}$ and $\mathrm{CN}$ ) responded optimally to low spatial and high temporal frequencies and displayed narrow spatial and temporal frequency tuning. The detailed statistical analysis also revealed that according to its stimulus preferences the SCs has markedly different spatio-temporal properties from the homogeneous group formed by the SCi, Sg and $\mathrm{CN}$. The SCs neurons preferred higher spatial and lower temporal frequencies and had broader spatial tuning than the other structures. In contrast to the SCs the visually active $\mathrm{SCi}$, as well as the $\mathrm{Sg}$ and the $\mathrm{CN}$ neurons possessed consequently similar spatio-temporal preferences. These data support our hypothesis that the visually active $\mathrm{SCi}, \mathrm{Sg}$ and $\mathrm{CN}$ neurons form a homogeneous neuronal population, given that they have a similar spatio-temporal frequency preference and a common function in processing of dynamic visual information.

These findings and other recent morphological and physiological studies have suggested a strong relationship between the Sg of the posterior thalamus and the input structure of the basal ganglia, the $\mathrm{CN}$ of the feline brain. Accordingly, to clarify if there is a real functional relationship between them during visual information processing, we investigated the temporal relations of simultaneously recorded neuronal spike trains of these two structures, looking for any significant cross-correlation between the spiking of the simultaneously recorded neurons. For the purposes of statistical analysis, we used the shuffle and jitter resampling methods. Of the recorded $288 \mathrm{Sg}-\mathrm{CN}$ neuron pairs, 26 $(9.2 \%)$ showed significantly correlated spontaneous activity. Nineteen pairs $(6.7 \%)$ showed correlated activity during stationary visual stimulation, while 21 (7.4\%) pairs during stimulus movement. There was no overlap between the neuron pairs that showed cross-correlated spontaneous activity and the pairs that synchronized their activity during visual stimulation. Thus, visual stimulation seems to have been able to synchronize, and also, by other neuron pairs, desynchronize the activity of $\mathrm{CN}$ and $\mathrm{Sg}$. In about half of the cases, the activation of $\mathrm{Sg}$ preceded the activation of $\mathrm{CN}$ by a few milliseconds, while in the other half, $\mathrm{CN}$ was activated earlier. We argue that either a monosynaptic bidirectional direct connection should exist between these structures, or a common input comprising of parallel pathways synchronizes them. 
In summary, our studies pointed out that:

1. There are similar spatio-temporal visual response profiles within the subcortical structure of the ascending tectofugal visual system

- low spatial and high temporal frequencies are preferred

- narrow spatial and temporal frequency tuning is displayed

These findings further support the hypothesis that the ascending tectofugal system of the feline brain plays important roles in sensory-motor coordination and may serve for perception of the visual environment during self-motion.

2. Physiological cooperation can be measured between the suprageniculate nucleus $(\mathrm{Sg})$ of the posterior thalamus and the caudate nucleus $(\mathrm{CN})$ - we can find temporal coupling between the outputs of the two structures. Furthermore:

- we could not determine unambiguously whether $\mathrm{Sg}$ or $\mathrm{CN}$ is the earlier stage of the information processing pathway with none of the analyzing methods

- bidirectional information flow between the $\mathrm{Sg}$ and $\mathrm{CN}$ is suggested

- monosynaptic, direct pathway or common input is assumed

We consider all the above mentioned findings to provide the first piece of evidence for the existence of a functional cooperation between $\mathrm{Sg}$ and $\mathrm{CN}$. 
I respectfully thank Professor Dr. György Benedek and Dr. Attila Nagy who have served as my mentors and supervisors, and for the opportunity that I could work with them. I greatly appreciate their helpful and instructive guidance. I express my gratitude to Professor Dr. Gábor Jancsó for allowing me to participate in the Neuroscience Ph.D. Program. My special thanks go to Dr. Zsuzsanna Paróczy, Dr. Antal Berényi, Dr. Zita Márkus, Dr. Gábor Braunitzer, Péter Gombkötő, Dr. Ágnes Farkas and Dr. Gabriella Eördegh for their help and friendship. I would like to acknowledge the help of Györgyi Utassy, Tamás Nagypál, Anett Nagy, Wioletta Waleszczyk and Marek Wypych, too.

I express my most sincere gratitude to Gabriella Dósai for her valuable technical assistance and for the preparation of high-quality figures for my thesis. Many thanks go to Péter Liszli for his expert help in solving hardware and software problems.

I would like to express my thanks to all of my colleagues and friends in the Department of Physiology for their support and kindness. It has been nice to work with them in this department.

My deepest thanks go to my parents Dr. Alice Árgyelán and Dr. Tibor Rokszin, my sister, Bereniké Rokszin, Sándor Kristó and all of my relatives and friends for their continuous love and help in my life and scientific work.

Our experiments were supported by OTKA/Hungary grant T042610, OTKA/Hungary grant 68594 . 


\section{REFERENCES}

[1] Abeles, M.; Gat, I. Detecting precise firing sequences in experimental data. J. Neurosci. Methods 107, 141-54. 2001.

[2] Adelson, E.H.; Movshon, J.A. Phenomenal coherence of moving visual patterns. Nature 300, 523-525. 1982.

[3] Aertsen, A.M.; Gerstein, G.L. Evaluation of neuronal connectivity: sensitivity of crosscorrelation. Brain Res. 340, 341-54. 1985.

[4] Albright, T.D.; Stoner, G.R. Visual motion perception. Proc. Natl. Acad. Sci. USA 92, 2433 2440. 1995.

[5] Alonso, J.M.; Martinez, L.M. Functional connectivity between simple cells and complex cells in cat striate cortex. Nat. Neurosci. 1, 395-403. 1998.

[6] Andersen, R.A. Neural mechanisms of visual motion perception in primates. Neuron 18, 865872. 1997.

[7] Anderson, S.J.; Burr, D.C. Spatial and temporal selectivity of the human motion detection system. Vision Res. 25, 1147-1154. 1985.

[8] Barneoud, P.; Descombris, E.; Aubin, N.; Abrous, D.N. Evaluation of simple and complex sensorimotor behaviours in rats with a partial lesion of the dopaminergic nigrostriatal system. Eur. J. Neurosci. 12, 322-336. 2000.

[9] Benedek, G.; Jang, E.K.; Hicks, T.P. Physiological properties of visually responsive neurons in the insular cortex of the cat. Neurosci. Lett. 64, 269-274. 1986.

[10] Benedek, G.; Mucke, L.; Norita, M.; Albowitz, B.; Creutzfeldt, O.D. Anterior ectosylvian visual area (AEV) of the cat: physiological properties. Prog. Brain Res. 75, 245-255. 1988.

[11] Benedek, G.; Perény, J.; Kovács, G.; Fischer-Szatmári, L.; Katoh, Y.Y. Visual, somatosensory, auditory and nociceptive modality properties in the feline suprageniculate nucleus. Neuroscience 78, 179-189. 1997.

[12] Berényi, A.; Benedek, G.; Nagy, A.; Double sliding-window technique: a new method to calculate the neuronal response onset latency. Brain Res. 1178, 141-8. 2007.

[13] Brainard, D.H., The Psychophysics Toolbox. Spat. Vis. 10, 433-6. 1997.

[14] Brown, V.J.; Desimone, R.; Mishkin, M.; Responses of cells in the tail of the caudate nucleus during visual discrimination learning. J. Neurophysiol. 74, 1083-1094. 1995.

[15] Burr, D.C.; Ross, J. Visual processing of motion. Trends Neurosci. 9, 304-307. 1986a

[16] Burr, D.C.; Ross, J.; Morrone, M. Seeing objects in motion. Proc. Roy. Soc. Lond. B. 227, 249265. $1986 b$

[17] Clifford C.W.G.; Ibbotson, M.R. Fundamental mechanisms of visual motion detection: models, cells and functions. Prog. Neurobiol. 68, 409-437. 2002.

[18] Cowie, R.J.; Robinson, D.L. Subcortical contributions to head movements in macaques. I. Contrasting effects of electrical stimulation of a medial pontomedullary region and the superior colliculus. J. Neurophysiol. 72, 2648-2664. 1994.

[19] de Oliveira, S.C.; Thiele, A.; Hoffmann, K.P. Synchronization of neuronal activity during stimulus expectation in a direction discrimination task. J Neurosci.17, 9248-60. 1997.

[20] De Valois, K.K.; De Valois, R.L.; Yund, E.W. Responses of striate cortex cells to grating and checkerboard patterns. J. Physiol. 291, 483-505. 1979.

[21] Derrington, A; Suero, M. Motion of complex patterns is computed from the perceived motions of their components. Vision Res. 31, 139-149. 1991.

[22] Enroth-Cugell, C.; Robson, J.G. The contrast sensitivity of retinal ganglion cells of the cat. $J$. Physiol. 187, 517-552. 1966.

[23] Eördegh, G.; Nagy, A.; Berényi, A.; Benedek, G., Processing of spatial visual information along the pathway between the suprageniculate nucleus and the anterior ectosylvian cortex. Brain Res. Bull. 67, 281-9. 2005. 
[24] Felleman, D.J.; Van Essen, D.C. Distributed hierarchical processing in the primate cerebral cortex. Cereb. Cortex 1, 1-47. 1991.

[25] Freedman, E.G.; Sparks, D.L. Activity of cells in the deeper layers of the superior colliculus of the rhesus monkey: evidence for a gaze displacement command. J. Neurophysiol. 78, 1669-1690. 1997.

[26] Fries, W. The projection from the lateral geniculate nucleus to the peristriate cortex of the macaque monkey. Proc. R. Soc. Lond. B. Biol. 213, 73-86. 1981.

[27] Fujisawa, S.; Amarashingham, A.; Harrison, M.T.; Buzsáki, G. Behavior-dependent short-term assembly dynamics in the medial prefrontal cortex. Nature Neurosci. 11, 823-33. 2008.

[28] Gochin, P.M.; Miller, E.K.; Gross, C.G.; Gerstein, G.L. Functional interactions among neurons in inferior temporal cortex of the awake macaque. Exp. Brain Res. 84, 505-16. 1991.

[29] Goodale, M.A.; Milner, A.D. Separate visual pathways for perception and action. Trends Neurosci. 15, 20-25. 1992.

[30] Gross, C.G. Contribution of striate cortex and the superior colliculus to visual function in area MT, the superior temporal polysensory area and the inferior temporal cortex. Neuropsychologia 29, 497-515. 1991.

[31] Guirado, S.; Real, M.A.; Dávila, J.C. The ascending tectofugal visual system in amniotes: new insights. Brain Res. Bull. 66, 290-6. 2005.

[32] Harting, J.K.; Updyke, B.V.; Van Lieshout, D.P. Striatal projections from the cat visual thalamus. Eur. J. Neurosci. 14, 893-896. 2001a

[33] Harting, J.K.; Updyke, B.V.; Van Lieshout, D.P. The visual-oculomotor striatum of the cat: functional relationship to the superior colliculus. Exp. Brain Res. 136, 138-142 2001b

[34] Hatsopoulos, N.G.; Geman, S.; Amarasingham, A.; Bienenstock, E. At what time scale does the nervous system operate. Neurocomputing 52-54, 25-29. 2003.

[35] Hicks, T.P.; Benedek, G.; Thurlow, G.A. Organization and properties of neurons in a visual area within the insular cortex of the cat. J. Neurophysiol. 60, 397-421. 1988.

[36] Hikosaka, O.; Sakamoto, M.; Usui, S. Functional properties of monkey caudate neurons. II. Visual and auditory responses. J. Neurophysiol. 61, 799-813. 1989.

[37] Hikosaka, O.; Takikawa, Y.; Kawagoe, R. Role of the basal ganglia in the control of purposive saccadic eye movements. Physiol. Rev. 80, 953-78. 2000.

[38] Hirabayashi, T.; Miyashita, Y. Dynamically modulated spike correlation in monkey inferior temporal cortex depending on the feature configuration within a whole object. J. Neurosci. 25, 10299-307. 2005.

[39] Hollander, H.; Tietze, J.; Distel, H. An autoradiographic study of the subcortical projections of the rabbit striate cortex in the adult and during postnatal development. J. Comp. Neurol. 184, $783-$ 794. 1979.

[40] Hoshino, K.; Eördegh, G.; Nagy, A.; Benedek, G.; Norita, M. Overlap of nigrothalamic terminals and thalamostriatal neurons in the feline lateralis medialis-suprageniculate nucleus. Acta Physiol. Hung. 96, 203-211. 2009a

[41] Hoshino, K.; Horie, M.; Nagy, A.; Berényi, A.; Benedek, G.; Norita, M. Direct synaptic connections between superior colliculus afferents and thalamo-insular projection neurons in the feline suprageniculate nucleus: A double-labeling study with WGA-HRP and kainic acid. Neurosci. Res. 66, 7-13. 2009b

[42] Hoshino, K.; Nagy, A.; Eördegh, G.; Benedek, G.; Norita, M., Two types of neuron are found within the PPT, a small percentage of which project to both the LM-SG and SC. Exp. Brain Res. 155, 421-6. 2004.

[43] Hu, H.; Jayaraman, A. The projection pattern of the suprageniculate nucleus to the caudate nucleus in cats. Brain Res. 368, 201-3. 1986.

[44] Hubel, D.H.; Wiesel, T.N. Receptive fields and functional architecture in two nonstriate visual areas (18 and 19) of the cat. J. Neurophysiol. 28, 229-89. 1965. 
[45] Hubel, D.H.; Wiesel, T.N. Receptive fields, binocular and functional architecture in the cat's visual cortex. J. Physiol. 160, 106-54. 1962

[46] Katoh, Y.Y.; Arai, R.; Benedek, G. Bifurcating projections from the cerebellar fastigial neurons to the thalamic suprageniculate nucleus and to the superior colliculus. Brain Res. 864, 308-11. 2000.

[47] Katoh, Y.Y.; Benedek, G. Organization of the colliculo-suprageniculate pathway in the cat: a wheat germ agglutinin-horseradish peroxydase study. J. Comp. Neurol. 352, 381-397. 1995.

[48] Katoh, Y.Y.; Benedek, G.; Deura, S. Bilateral projections from the superior colliculus to the suprageniculate nucleus in the cat: a WGA-HRP/double fluorescent tracing study. Brain Res. 669, 298-302. 1995.

[49] Kolomiets, B. A possible visual pathway to the cat caudate nucleus involving the pulvinar. Exp. Brain Res. 97, 317-24. 1993.

[50] Lennie, P. Parallel visual pathways: a review. Vision Res. 20, 561-94. 1980.

[51] Li, B.; Chen, Y.; Li, B.W.; Wang, L.H.; Diao, Y.C. Pattern and component motion selectivity in cortical area PMLS of the cat. Eur. J. Neurosci. 14, 690-700. 2001.

[52] Li, B.; Li, B.W.; Chen, Y.; Wang, L.H.; Diao, Y.C. Response properties of PMLS and PLLS neurons to stimulated optic flow patterns. J. Neurosci. 12, 1534-1544. 2000.

[53] Lynd-Balta, E.; Haber, S.N. The organization of midbrain projections to the striatum in the primate: sensorimotor-related striatum versus ventral striatum. Neuroscience 59, 625-640. 1994.

[54] Márkus, Z.; Berényi, A.; Paróczy, Z.; Wypych, M.; Waleszczyk, W.J.; Benedek, G. Spatial and temporal visual properties of the neurons in the intermediate layers of the superior colliculus. Neurosci. Lett. 454, 76-80. 2009.

[55] McHaffie, J.G.; Stanford, T.R.; Stein, B.E.; Coizet, V.; Redgrave, P. Subcortical loops through the basal ganglia. Trends Neurosci. 28, 401-7. 2005.

[56] Melssen, W.J.; Epping, W.J. Detection and estimation of neural connectivity based on crosscorrelation analysis. Biol. Cybern. 57, 403-14. 1987.

[57] Meredith, M.A.; Stein, B.E., Visual, auditory, and somatosensory convergence on cells in superior colliculus results in multisensory integration. J. Neurophysiol. 56, 640-662. 1986.

[58] Miceli, D.; Reperant, J.; Ptito, M. Intracortical connections of the anterior ectosylvian and lateral suprasylvian visual areas in the cat. Brain Res. 347, 291-298. 1985.

[59] Mimeault, D.; Paquet, V.; Molotchnikoff, S.; Lepore, F.; Guillemot, J.P. Disparity sensitivity in the superior colliculus of the cat. Brain Res. 1010, 87-94. 2004.

[60] Mucke, L.; Norita, M.; Benedek, G.; Creutzfeldt, O. Physiologic and anatomic investigation of a visual cortical area situated in the ventral bank of the anterior ectosylvian sulcus of the cat. Exp. Brain Res. 46, 1-11. 1982.

[61] Nagy, A.; Eördegh, G.; Benedek G. Spatial and temporal visual properties of single neurons in the feline anterior ectosylvian visual area. Exp. Brain Res. 151, 108-114. 2003a

[62] Nagy, A.; Eördegh, G.; Benedek, G. Extents of visual, auditory and bimodal receptive fields of single neurons in the feline visual associative cortex. Acta Physiol Hung. 90, 305-12. 2003b

[63] Nagy, A.; Eördegh, G.; Norita, M.; Benedek, G. Visual receptive field properties of neurons in the caudate nucleus. Eur. J. Neurosci. 18, 449-452. 2003c

[64] Nagy, A.; Paróczy, Z.; Márkus, Z.; Berényi, A.; Wypych, M.; Waleszczyk, W.J.; Benedek, G. Drifting grating stimulation reveals particular activation properties of visual neurons in the caudate nucleus. Eur J Neurosci. 27, 1801-8. 2008.

[65] Nakayama, K. Biological image motion processing: A review. Vis. Res. 25, 625-660. 1985.

[66] Nassi, J.J.; Callaway, E.M. Parallel processing strategies of the primate visual system. Nat. Rev. Neurosci. 10, 360-372. 2009.

[67] Norita, M.; Hicks, T.P.; Benedek, G.; Katoh, Y.Y. Organization of cortical and subcortical projections to the feline insular visual area, IVA. J. Hirnforsch. 32, 119-134. 1991.

[68] Norita, M.; Mucke, L.; Benedek, G.; Albowitz, B.; Katoh, Y.Y.; Creutzfeldt, O.D. Connections of the anterior ectosylvian visual area (AEV). Exp. Brain Res. 62, 225-240. 1986. 
[69] Nowak, L.G.; Bullier, J., The timing of information transfer in the visual system. In: Rockland, K.S., Kaas, J.H., Peters, A. (Eds.), Cerebral cortex, vol. 12. Extrastriate cortex in primates. Plenum Press, New York, pp. 205-241. 1997.

[70] Nowak, L.G.; Munk, M.H.; Nelson, J.I.; James, A.C.; Bullier, J. Structural basis of cortical synchronization. I. Three types of interhemispheric coupling. J. Neurophysiol. 74, 2379-400. 1995.

[71] Olson, C.R.; Graybiel, A.M. An outlying visual area in the cerebral cortex of the cat. Prog. Brain Res. 58, 239-245. 1983.

[72] Olson, C.R.; Graybiel, A.M. Ectosylvian visual area of the cat: location, retinotopic organization, and connections. J. Comp. Neurol. 261, 277-294. 1987.

[73] Ouellette, B.G.; Casanova, C. Overlapping visual response latency distributions in visual cortices and LP-pulvinar complex of the cat. Exp. Brain Res. 175, 332-41. 2006.

[74] Ouellette, B.G.; Minville, K.; Faubert, J.; Casanova, C. Simple and complex visual motion response properties in the anterior medial bank of the lateral suprasylvian cortex. Neuroscience 123, 231-245. 2004.

[75] Palmer, L.A.; Rosenquist, A.C.; Tusa, R.J. The retinotopic organization of lateral suprasylvian visual areas in the cat. J. Comp. Neurol. 177, 237-256. 1978.

[76] Paróczy, Z.; Nagy, A.; Márkus Z.; Waleszczyk, W.J.; Wypych, M; Benedek, G., Spatial and temporal visual properties of single neurons in the suprageniculate nucleus of the thalamus. Neuroscience 137, 1397-1404. 2006.

[77] Payne, B.R. Evidence for visual cortical area homologs in cat and macaque monkey. Cereb. Cortex 3, 1-25. 1993.

[78] Pelli, D.G. The VideoToolbox software for visual psychophysics: transforming numbers into movies. Spat. Vis. 10, 437-42. 1997.

[79] Perkel, D.H.; Gerstein, G.L.; Moore, G.P. Neuronal spike trains and stochastic point processes. II. Simultaneous spike trains. Biophys. J. 7, 419-40. 1967.

[80] Pinter, R.B.; Harris, L.R. Temporal and spatial response characteristics of the cat superior colliculus. Brain Res. 207, 73-94. 1981.

[81] Pouderoux, C.; Freton, E. Patterns of unit responses to visual stimuli in the cat caudate nucleus under chloralose anesthesia. Neurosci. Lett. 11, 53-58. 1979.

[82] Rodman, H.R.; Gross, C.G.; Albright, T.D. Afferent basis of visual response properties in area MT of the macaque. I. Effects of striate cortex removal. J. Neurosci. 9, 2033-2050. 1989.

[83] Rodman, H.R.; Gross, C.G.; Albright, T.D. Afferent basis of visual response properties in area MT of the macaque. II. Effects of superior colliculus removal. J. Neurosci. 10, 1154-1164. 1990.

[84] Rolls, E.T., Thorpe; S.J.; Maddison, S.P. Responses of striatal neurons in the behaving monkey. 1. Head of the caudate nucleus. Behav. Brain Res. 7, 179-210. 1983.

[85] Rosenquist A.C. Connections of visual Cortical Areas in the Cat. In Cerebral Cortex; Peters, A., Jones, E.G., (Eds.), Visual Cortex, vol. 3., Plenum Press: New York, NY, USA, pp. 81-117. 1985.

[86] Saul, A.B.; Humphrey, A.L. Spatial and temporal response properties of lagged and nonlagged cells in cat lateral geniculate nucleus. J. Neurophysiol. 64, 206-224. 1990.

[87] Schoenfeld, M.A.; Heinze, H.-J.; Woldorff, M.G. Unmasking motion-processing activity in human brain area $\mathrm{V} 5 / \mathrm{MT}+$ mediated by pathways that bypass primary visual cortex. Neuroimage 17, 769-779. 2002.

[88] Schwarz, M.; Sontag, K.H.; Wand, P. Sensory-motor processing in substantia nigra pars reticulata in conscious cats. J. Physiol. (Lond.) 347, 129-147. 1984.

[89] Sprague, J.M. The role of the superior colliculus in facilitating visual attention and form perception, Proc. Natl. Acad. Sci. USA 88, 1286-1290. 1991.

[90] Standage, G.P.; Benevento, L.A. The organization of connections between the pulvinar and visual area MT in the macaque monkey. Brain Res. 262, 288-294. 1983.

[91] Stein, B.E.; Meredith M.A. Functional organization of the superior colliculus, In: Leventhal A.G., (Ed.), The neural basis of visual function. Macmillan, UK, 1991 
[92] Stein, B.E.; Meredith, M.A. The Merging of the Sense; The MIT Press: Cambridge, MA, USA, 1993.

[93] Stepniewska, I.; Qi, H.X.; Kaas, J.H. Do superior colliculus projection zones in the inferior pulvinar project to MT in primates? Eur. J. Neurosci. 11, 469-480. 1999.

[94] Stone, J.; Dreher, B.; Leventhal, A. Hierarchical and parallel mechanisms in the organization of visual cortex. Brain Res. 180, 345-94. 1979.

[95] Strecker, E.R.; Steinfels, G.; Abercrombie, E.D.; Jacobs, B.L. Caudate unit activity in freely moving cats: effects of phasic auditory and visual stimuli. Brain Res. 329, 350-353. 1985.

[96] Symonds, L.L.; Rosenquist, A.C. Corticocortical connections among visual areas in the cat. $J$. Comp. Neurol. 229, 1-38. 1984a

[97] Symonds, L.L.; Rosenquist, A.C. Laminar origins of visual corticocortical connections in the cat. J. Comp. Neurol. 229, 39-47. 1984b

[98] Takada, M.; Itoh, K.; Yasui, Y.; Sugimoto, T.; Mizuno, N. Topographical projections from the posterior thalamic regions to the striatum in the cat, with reference to possible tecto-thalamostriatal connections. Exp. Brain Res. 60, 385-396. 1985.

[99] Tusa, R.J.; Palmer, L.A.; Rosenquist, A.C. The retinotopic organization of area 17 (striate cortex) in the cat. J. Comp. Neurol. 177, 213-235. 1978.

[100] Ungerleider, L.G.; Mishkin M. Two cortical visual systems. In Ingle, D.J., Goodale, M.A., Mansfield, R.J.W., (Eds.) Analysis of Visual Behavior; MIT Press: Cambridge, MA, USA, pp. 549-586. 1982.

[101] Villeneuve, M.Y.; Casanova, C. On the use of isoflurane versus halothane in the study of visual response properties of single cells in the primary visual cortex. J. Neurosci. Meth. 129, 19-31. 2003.

[102] Waleszczyk, W.J.; Nagy, A.; Wypych, M.; Berényi, A.; Paróczy, Z.; Eördegh, G. Spectral receptive field properties of neurons in the feline superior colliculus. Exp. Brain Res. 181, 87-98 2007.

[103] Wang, C.; Dreher, B.; Assaad, N.; Ptito, M.; Burke, W. Excitatory convergence of Y and non$\mathrm{Y}$ channels onto single neurons in the anterior ectosylvian visual area of the cat. Eur. J. Neurosci. 10, 2945-2956. 1998.

[104] Webster, K.E. The cortico-striatal projections in the cat. J. Anat. 99, 329-337. 1965.

[105] Weiskrantz, L. Blindsight. A Case Study and Implications. Clarendon Press, Oxford, 1986.

[106] Welch, L. The perception of moving plaids reveals two motion-processing stages. Nature 337, 734-736. 1989.

[107] Werner, W.; Dannenberg, S.; Hoffmann, K.P. Arm-movement-related neurons in the primate superior colliculus and underlying reticular formation: comparison of neuronal activity with EMGs of muscles of the shoulder, arm and trunk during reaching. Exp. Brain Res. 115, 191-205. 1997.

[108] Wurtz, R.H.; Albano, J.E. Visual-motor function of the primate superior colliculus. Annu. Rev. Neurosci. 3, 189-226. 1980.

[109] Yukie, M.; Iwai, E. Direct projection from the dorsal lateral geniculate nucleus to the peristriate cortex in macaque monkey. J. Comp. Neurol. 201, 81-97. 1981.

[110] Zeki, S.; Watson, J.D.; Lueck, C.J.; Friston, K.J.; Kennard, C.; Frackowiak, R.S. A direct demonstration of functional specialization in human cortex. J. Neurosci. 11, 641-649. 1991.

[111] Zeki, S.M. Functional organization of a visual area in the posterior bank of the superior temporal sulcus of the rhesus monkey. J. Physiol. 236, 549-573. 1974.

[112] Zumbroich, T.; Price, D.J.; Blakemore, C. Development of spatial and temporal selectivity in the suprasylvian visual cortex of the cat. J. Neurosci. 8, 2713-2728. 1988. 